\title{
A Short Splice Form of Xin-Actin Binding Repeat Containing 2 (XIRP2) Lacking the Xin Repeats Is Required for Maintenance of Stereocilia Morphology and Hearing Function
}

\author{
Shimon P. Francis, ${ }^{1}$ Jocelyn F. Krey, ${ }^{4}$ Evan S. Krystofiak, ${ }^{5}$ Runjia Cui, ${ }^{5}$ Sonali Nanda, ${ }^{1}$ Wenhao Xu, ${ }^{3}$ Bechara Kachar, ${ }^{5}$ \\ 일 Peter G. Barr-Gillespie, ${ }^{4}$ and Jung-Bum Shin ${ }^{1,2}$ \\ ${ }^{1}$ Departments of Neuroscience, ${ }^{2}$ Brain, Immunology, and Glia Center, and ${ }^{3}$ Gene Targeting and Transgenic Facility, University of Virginia, Charlottesville, \\ Virginia 22908, ${ }^{4}$ Oregon Hearing Research Center \& Vollum Institute, Oregon Health \& Science University, Portland, Oregon 97239, and ${ }^{5 N a t i o n a l ~ I n s t i t u t e ~}$ \\ for Deafness and Communications Disorders, National Institute of Health, Bethesda, Maryland 20892
}

\begin{abstract}
Approximately one-third of known deafness genes encode proteins located in the hair bundle, the sensory hair cell's mechanoreceptive organelle. In previous studies, we used mass spectrometry to characterize the hair bundle's proteome, resulting in the discovery of novel bundle proteins. One such protein is Xin-actin binding repeat containing 2 (XIRP2), an actin-cross-linking protein previously reported to be specifically expressed in striated muscle. Because mutations in other actin-cross-linkers result in hearing loss, we investigated the role of XIRP2 in hearing function. In the inner ear, XIRP2 is specifically expressed in hair cells, colocalizing with actin-rich structures in bundles, the underlying cuticular plate, and the circumferential actin belt. Analysis using peptide mass spectrometry revealed that the bundle harbors a previously uncharacterized XIRP2 splice variant, suggesting XIRP2's role in the hair cell differs significantly from that reported in myocytes. To determine the role of XIRP2 in hearing, we applied clustered regularly interspaced short palindromic repeat (CRISPR)/Cas9-mediated genome-editing technology to induce targeted mutations into the mouse Xirp2 gene, resulting in the elimination of XIRP2 protein expression in the inner ear. Functional analysis of hearing in the resulting Xirp2-null mice revealed high-frequency hearing loss, and ultrastructural scanning electron microscopy analyses of hair cells demonstrated stereocilia degeneration in these mice. We thus conclude that XIRP2 is required for long-term maintenance of hair cell stereocilia, and that its dysfunction causes hearing loss in the mouse.
\end{abstract}

Key words: CRISPR; hair bundle; hair cell; hearing; stereocilia; XIRP2

\section{Introduction}

Hearing loss is the most prevalent human sensory impairment in the modern world, affecting $>28$ million Americans (Mathers et al., 2001; Friedman and Griffith, 2003; Dror and Avraham, 2009), with an estimated $50-60 \%$ of hearing loss in children attributable to genetic defects (Van Camp et al., 1997; Steel and Kros, 2001; Friedman and Griffith, 2003; Morton and Nance, 2006; Raviv et al., 2010; Shearer and Smith, 2012). Strikingly, approximately one-third of all known deafness genes code for proteins

\footnotetext{
Received Aug. 18, 2014; revised Dec. 9, 2014; accepted Dec. 11, 2014.

Author contributions: S.P.F., J.F.K., E.S.K., W.X., B.K., P.G.B.-G., and J.-B.S. designed research;S.P.F., J.F.K., E.S.K., R.C., S.N., W.X., B.K., P.G.B.-G., and J.-B.S. performed research; S.P.F., J.F.K., E.S.K., B.K., P.G.B.-G., and J.-B.S. analyzed data; S.P.F., P.G.B.-G., and J.-B.S. wrote the paper.

This study was funded by National Institutes of Health-National Institute for Deafness and Communication Disorders grants R01 DC014254 and K99/R00 DC009412 to J.B.S. and R01 DC002368, R01 DC011034, and P30 DC005983 to P.G.B.-G. We thank James Pagana, Ben Thiede, and Jeff Corwin for helping with the SEM preparations. The authors declare no competing financial interests.

Correspondence should be addressed to Jung-Bum Shin, Department of Neuroscience, University of Virginia, Charlottesville, VA 22908. E-mail: js2ee@virginia.edu.

DOI:10.1523/JNEUROSCI.3449-14.2015

Copyright $\odot 2015$ the authors $\quad 0270-6474 / 15 / 351999-16 \$ 15.00 / 0$
}

localized to the hair bundle (Raviv et al., 2010), an organelle solely dedicated to mechanoelectrical transduction (Hudspeth, 1989; Gillespie and Walker, 2001). We previously used a peptide mass spectrometry-based strategy to characterize the hair bundle proteome, with the goal to discover novel proteins involved in hearing and deafness (Shin et al., 2007, 2013). As a result, we identified and quantified $>1100$ bundle proteins, many of which were previously unidentified within hair cells. As expected for an organelle rich in F-actin, our proteomics screen identified actinbinding proteins to be among the most enriched and abundant proteins within the bundle. One such protein was Xin-actin binding repeat containing 2 (XIRP2; synonyms CMYA3, Xin- $\beta$, and Myomaxin), an actin cross-linking protein that is located at the Z-disk/costameric region and the intercalated disk of the striated muscle (Huang et al., 2006; Q. Wang et al., 2012). Complete loss of XIRP2 causes diastolic dysfunction and early postnatal mortality in mice (Q. Wang et al., 2010), suggesting that it might play a role in the development and maturation of the intercalated disks (Q. Wang et al., 2010, 2013). Because previous studies have reported that XIRP2 is specific for cardiac and skeletal muscle (Huang et al., 2006; Q. Wang et al., 2012), our discovery of XIRP2 
in sensory hair cells came as a surprise. The genetic locus of the Xirp2 gene overlaps with two unresolved human deafness loci (DFNB27 and DFNA16; Fukushima et al., 1999; Pulleyn et al., 2000), making its study significant for deafness research.

In this study, we investigate the role of XIRP2 in sensory hair cell function. Proteomics and immunocytochemical analyses demonstrate that XIRP2 is specifically localized to the stereocilia and the pericuticular necklace region of the hair cell. Furthermore, we show that the hair bundle harbors a short splice isoform that is distinct from the previously characterized variant expressed in striated muscle. Finally, we used the clustered regularly interspaced short palindromic repeat (CRISPR)/Cas9 system (Cong et al., 2013; Hwang et al., 2013; Mali et al., 2013; H. Wang et al., 2013), a recently developed method for highly efficient genome editing, to disrupt the Xirp2 gene in the mouse and demonstrate that XIRP2 is crucial for maintenance of hearing function.

\section{Materials and Methods}

Animal care and handling. Animal protocols were approved by the Institutional Animal Care and Use Committees of the University of Virginia, the National Institute on Deafness and Other Communication Disorders, and the Oregon Health \& Science University. All institutions are accredited by the American Association for the Accreditation of Laboratory Animal Care. Chick embryos before hatching are exempt from animal care guidelines, but when killing chick embryos, we nevertheless followed guidelines established for vertebrates (rapid decapitation using sharp scissors). All mouse experiments were performed using the CD1, CBA/J, C57BL/6 inbred mouse strains, or C57BL/6J-SJL mixed background mice. Neonatal mouse pups (P3-P4) were killed by rapid decapitation; mature mice were killed by $\mathrm{CO}_{2}$ asphyxiation, followed by cervical dislocation. Neonatal rat pups (P3) were killed by rapid decapitation.

Preparation of samples for mass spectrometry. Utricle hair bundles were purified from E20-E21 chicks, and P3-P4 CD1 mouse pups using the previously described twist-off method (Shin et al., 2009). Processing of purified mouse hair bundles for mass spectrometry analysis was performed following the low-abundance protein protocol accompanying the ProteaseMAX surfactant reagent from Promega (V2071) and was similar to chick tissue processing described previously (Shin et al., 2013). In brief, purified hair bundles, in agarose, were solubilized in SDS-PAGE sample buffer; proteins were run $\sim 1 \mathrm{~cm}$ into an SDS acrylamide gel and stained with Imperial Protein Stain (Thermo Scientific). Equally spaced slices of gel were cut out with a scalpel; gel pieces were then alkylated and reduced. After digestion of the sample with trypsin for $4 \mathrm{~h}$ (mouse) or overnight (chick) at $37^{\circ} \mathrm{C}$, peptides formed were extracted from the polyacrylamide in two $30 \mu \mathrm{l}$ aliquots of $50 \%$ acetonitrile $/ 5 \%$ formic acid (chick) or 2.5\% trifluoroacetic acid (mouse). These extracts were combined and evaporated to 5-15 $\mu \mathrm{l}$ for mass spectrometry analysis.

Mass spectrometry data acquisition and analysis. The LC-MS/MS system consisted of a Thermo Electron Orbitrap Velos ETD mass spectrometer system. Peptides were introduced into the mass spectrometer with a Protana nanospray ion source, which was interfaced to a reversed-phase capillary column of $8 \mathrm{~cm}$ length $\times 75 \mu \mathrm{m}$ internal diameter, self-packed with Phenomenex C18 Jupiter of $10 \mu \mathrm{m}$ particle size. An extract aliquot $(7.5 \mu \mathrm{l})$ was injected and peptides eluted from the column by an acetonitrile/0.1 M acetic acid gradient at a flow rate of $0.5 \mu \mathrm{l} / \mathrm{min}$ over $1.2 \mathrm{~h}$. The nanospray ion source was operated at $2.5 \mathrm{kV}$. The digest was analyzed using the data-dependent capability of the instrument, acquiring - in sequential scans-a single full-scan mass spectrum in the Orbitrap detector at 60,000 resolutions to determine peptide molecular weights, and 20 product-ion spectra in the ion trap to determine amino acid sequence. MaxQuant version 1.2.2.5 software was used for protein identification and quantitation (Cox and Mann, 2008).

$R T-P C R$. Whole heart and inner ear tissue (organ of Corti and utricle) were dissected from P3 mouse pups, and total RNA was extracted using the TRIzol reagent (Life Technologies) and treated with DNase I
(Qiagen). Oligo(dT)-primed cDNA synthesis was performed using the SuperScript Reverse Transcriptase II kit (Life Technologies). The following PCR primers were used for amplifying full-length and fragments of XIRP2: full-length short XIRP2: up: GCGGACAATCTGGAGCCAT, low: TCAGTCAGCCTCGCTGTC; exon -7 to 2: up: GCGGACAAT CTGGAGCCAT, low: CCTCTCCTTCAGGGACAGC; exon 6-7: up: TCATTGATTCGCCAGAAGAAG, low: TCTTTGCTTGGAGTATAAATCTTTGG; Exon 6-9: up: TCATTGATTCGCCAGAAGAAG, low: TTGAATTCTTCCTCAGGGGG.

Immunocytochemistry. Tissues were fixed for $15 \mathrm{~min}$ in 3\% formaldehyde. After blocking for $1 \mathrm{~h}$ with $1 \%$ bovine serum albumin, $3 \%$ normal donkey serum, and $0.2 \%$ saponin in PBS (blocking buffer), organs were incubated overnight at $4^{\circ} \mathrm{C}$ with primary antibodies in blocking buffer. Organs were then washed $3 \times 5$ min with PBS and incubated with secondary antibodies $(7.5 \mu \mathrm{g} / \mathrm{ml}$ Alexa 647, Alexa 488, Alexa 546conjugated donkey anti-rabbit IgG, donkey anti-mouse IgG, and donkey anti-goat IgG; Invitrogen) and $0.25 \mu \mathrm{M}$ phalloidin-Alexa 488 (Invitrogen) in blocking buffer for 1-3 h. Finally, organs were washed five times in PBS and mounted in Vectashield (Vector Laboratories). Samples were imaged using Zeiss LSM700 and Leica confocal microscopes. The following antibodies were used: rabbit anti-chick XIRP2 (generated against the epitope sequence SQLSLGNYASLHGQI on ENSGALP00000017765) and goat anti-XIRP2 (D-18, sc-83128; Santa Cruz Biotechnology). The epitope of the D-18 antibody is not disclosed by the vendor, but based on results described in Figure 6, D-18 recognizes both the short and the long XIRP2 isoform expressed in the hair cell. Rabbit anti-XIRP2 exon -6 (AAS27477C; Antibody Verify), rabbit anti-XIRP2 exon 7 (AAS26477C; Antibody Verify), rabbit anti-XIRP2 exon 9 (generated against the epitope sequence NSKRQDNDLRKWGD encoded by exon 9 of the mouse Xirp2 gene), rabbit anti-non-muscle myosin heavy chain II-C polyclonal antibody (PRB-444P; Covance), and mouse monoclonal anti$\alpha$-actinin 4 antibody (BM-75.2; Sigma).

Cell culture. HEK293 cells were cultured in high-glucose DMEM (\#11965 Life Technologies) supplemented with L-glutamine, $1 \mathrm{~mm}$ sodium pyruvate (Life Technologies), $100 \mathrm{U} / \mathrm{ml}$ penicillin, and $100 \mu \mathrm{g} / \mathrm{ml}$ streptomycin (Life Technologies), and 10\% FBS (Life Technologies). CL-4 cells were cultured in MEM Alpha (\#12561-072; Life Technologies) supplemented with L-glutamine, $100 \mathrm{U} / \mathrm{ml}$ penicillin, and $100 \mu \mathrm{g} / \mathrm{ml}$ streptomycin, and $10 \%$ FBS. All cells were maintained at $37^{\circ} \mathrm{C}, 5 \%$ $\mathrm{CO}_{2}$.

Gene gun-mediated transfection of mouse utricle explant cultures. P1 mouse utricles were dissected in HBSS (Life Technologies) with $25 \mathrm{~mm}$ HEPES, pH 7.5. The otoconia were removed using fine forceps and the utricles were stuck down onto the bottom of sterile $35 \mathrm{~mm}$ Petri dishes (part \#35001; BD Falcon), hair bundle side facing up. The dissection medium was replaced by two exchanges with culture medium containing complete high-glucose DMEM (Invitrogen), containing 1\% FBS, supplemented with ampicillin (Fisher Scientific) and ciprofloxacin (LKT Laboratories) antibiotics. After explants were cultured at $37^{\circ} \mathrm{C}$ in a $\mathrm{CO}_{2}$ incubator overnight, the medium was aspirated off the culture dish. The subsequent steps were conducted quickly to prevent the organ culture from drying out. A PDS-1000 (Bio-Rad) was used for biolistic gene gun transfections. In brief, plasmid DNA was precipitated on $1 \mu \mathrm{m}$ gold particles (following Bio-Rad protocol) and "shot" at the surface of the cultured utricles. A pressure of 900 psi was used. Immediately after the shot, complete growth medium was introduced to the culture dish, and explants were cultured for another $24 \mathrm{~h}$. Additional staining procedures were same as described in the previous section.

Transmission electron microscopy sample preparation. Inner ear tissue was prepared using a hybrid method involving initial fixation followed by high-pressure freezing as described previously (Bullen et al., 2014). Briefly, utricles and organ of Corti were isolated from the inner ear in $4 \%$ formaldehyde and $0.5 \%$ glutaraldehyde in HBSS and allowed to fix overnight. The tissue was cryoprotected with $30 \%$ glycerol and rapidly frozen using a Leica EMPACT2 high-pressure freezer. Frozen samples were freeze substituted and immunolabeled as previously described (Dumont et al., 2001). In brief, samples were freeze substituted in $1.5 \%$ uranyl acetate in methanol followed by embedding in Lowicryl resin. Ultrathin sections between 70 and $100 \mathrm{~nm}$ were blocked in normal goat serum, 
incubated with rabbit anti-XIRP2 exon -6 or rabbit anti-espin (Rzadzinska et al., 2005) primary antibodies for $2 \mathrm{~h}$, and labeled with anti-rabbit secondary antibody conjugated to $10 \mathrm{~nm}$ colloidal gold. Transmission electron microscopy was performed using a Zeiss 922 Omega TEM at 160 $\mathrm{kV}$ using a Gatan UltraScan camera.

Scanning electron microscopy sample preparation. Adult mice (6-8 weeks) were killed via $\mathrm{CO}_{2}$ asphyxiation; animals were perfused intracardially, first with PBS and then with $4 \%$ formaldehyde. The cochlea was isolated and a piece of bone was removed from the apex to create an opening. The stapes and oval window were then removed, and fixative ( $2.5 \%$ glutaraldehyde, in $0.1 \mathrm{M}$ cacodylate buffer, with $3 \mathrm{mM} \mathrm{CaCl}_{2}$ ) was perfused through the apical and basal openings. Cochleae were incubated in fixative overnight at $4^{\circ} \mathrm{C}$, then were decalcified in $4 \%$ EDTA, pH 7.3, for 3-4 $\mathrm{d}$ at room temperature. After the tectorial membrane was removed, the organ of Corti was dissected from the cochlea and was postfixed in $1 \% \mathrm{OsO}_{4}, 0.1 \mathrm{~m}$ cacodylate buffer, and $3 \mathrm{~mm} \mathrm{CaCl}_{2}$. The tissue was then processed by the thiocarbohydrazide- $\mathrm{OsO}_{4}$ protocol (Davies and Forge, 1987). Cochleae were then dehydrated through a series of graded ethanol incubations, critical point dried, and mounted on stubs. After sputter coating with gold, they were imaged on a Zeiss Sigma VP HD field emission SEM using the secondary electron detector.

CRISPR/Cas-mediated generation of Xirp2-null mice. Cas9 endonuclease mRNA was generated using the plasmid MLM3613 (provided by Keith Joung's lab through Addgene) as a template. Detailed instructions were published previously (Hwang et al., 2013). In brief, MLM3613 was linearized using PmeI-restriction digest, column purified, and used as a template for in vitro transcription (IVT) using the mMessage mMachine Ultra T7 transcription kit, which includes the reagents for polyadenylation of the IVT product (catalog \#AM1345; Life Technologies). After LiCl precipitation, Cas $9 \mathrm{mRNA}$ was adjusted to $1 \mathrm{mg} / \mu \mathrm{l}$ and stored in aliquots at $-80^{\circ}$ Celsius.

The target sequence was chosen using the "CRISPR Design" bioinformatics tool, developed by Feng Zhang's lab at the Massachusetts Institute of Technology (crispr.mit.edu). CRISPR Design identifies potential guides by analyzing the target sequence for $20 \mathrm{nt}$, followed by a protospacer adjacent motif (PAM), which is "NGG" in the case of the Streptococcus pyogenes Cas9. CRISPR Design also evaluates possible off-target mutation sites, using an algorithm developed using experimental data of the mismatch position effect on targeting (Hsu et al., 2013). The target oligonucleotide (GGTACCAGGCAGCTGTTTC on Xirp2 exon 2) was cloned downstream of the T7 promoter in the pDR274 vector (provided by Keith Joung's lab through Addgene). IVT was performed using the MAXIscript T7 kit (Life Technologies) and RNA was purified using the MEGAclear kit (Life Technologies).

Mouse zygote injections. B6SJLF1 female mice (The Jackson Laboratory) were superovulated and mated with B6SJLF1 males. The females were killed and the fertilized eggs were isolated from the oviducts. The fertilized eggs were co-injected with the purified Cas9 RNA $(100 \mathrm{ng} / \mu \mathrm{l})$ and sgRNA $(30 \mathrm{ng} / \mu \mathrm{l})$ under a Leica inverted microscope equipped with Leitz micromanipulators (Leica Microsystems). Injected eggs were incubated overnight in KSOM-AA medium (Millipore). Two-cell stage embryos were implanted on the following day in the oviducts of pseudopregnant ICR female mice (Taconic). Pups were screened by PCR and founders identified by DNA sequencing of the amplicons for the presence of indels. For mouse genotyping, genomic DNA was extracted from mouse tail clips. Briefly, tails were digested in alkaline lysis buffer (25 mu NaOH and $0.2 \mathrm{~mm}$ disodium EDTA, $\mathrm{pH} 12$ ) for $1 \mathrm{~h}$ at $95^{\circ} \mathrm{C}$, after which an equal volume of neutralization buffer $(40 \mathrm{~mm}$ Tris $\mathrm{HCl})$ was added. The genomic region surrounding the Xirp2 exon 2 target site was PCR amplified (genotyping primers: up: GTTTTCAGTGACCTTTAACCTTACTAA and low: CCGAGGCTTCAAGTCAGAAG). PCR products were purified using the PureLink Quick Gel Extraction Kit (Life Technologies) and subjected to DNA sequencing (Eurofins Genomics).

Sequencing of potential off-target mutations. Using the web-based CRISPR Design tool available on crispr.mit.edu (Zhang lab), which scores the specificity of CRISPR-amenable sites based on sequence homology and other criteria (Hsu et al., 2013), we identified 15 genomic loci as potential off-target sites of our CRISPR/Cas9-based Xirp2targeting strategy. The following genes were genotyped (gene name, followed by the sequence of the potential off-target site and the chromosome number): SEC31 homolog A (Sec31A) GGTACCACGCTCCTGTTTCAAGG, chr. 5; regulatory associated protein of MTOR, complex 1 (Rptor) CCATGACACAGCCCCCTGGTTCC, chr. 11; scavenger receptor class B, member 1 (Scarb1) AGTCTCAGGCAGCTGTTGCAGAG chr. 5; protein tyrosine phosphatase, receptor type Q (Ptprq) CCGTGAAACAGTTGTCTGGTGTC chr. 10; family with sequence similarity 181, member B (Fam 181b) CCTTCAAACAGCTCCCTGGTGTC chr. 7; myotubularin related protein 10 (Mtmr10) GGTGCCAGGCAGCTGTCCCATAG chr. 7; tectonin $\beta$-propeller repeat containing 1 (Tecpr 1 ) GGTCACAGGCAGCTCTTTCCCGG chr. 5; leucine-rich repeats and calponin homology domain containing 4 (Lrch4) GGAGCTAGGCAGCTGCTTCAGGG chr. 5; D- aspartate oxidase (Ddo) GATACCAGACTGCTTTTTCAGAG chr. 10; SH2 domain protein 2A (Sh2d2a), transcript variant 2 AGGACCAGGCAGCTGACTCACAG chr. 3; farnesyltransferase, CAAX box, $\beta$ (Fntb) GGAACCAGACTGCTGGTTCAGAG chr. 12; tryptophan hydroxylase 1 (Tph1), transcript variant 1 GGCACCAGGTAGCACTTTCAAGG chr. 7; RIKEN cDNA 4930415O20 gene (4930415O20Rik) GGTACCAGGAAGCTGTGCGAAAG chr. 15; enhancer of mRNA decapping 3 homolog (Saccharomyces cerevisiae) (Edc3) GGTACAAGGCAGCTGTGGCCTGG chr. 9; RIKEN cDNA 1500017E21 gene (1500017E21Rik) GGTATCAGGCAGCCTTGTCATGG chr. 19.

Auditory brainstem response. Auditory brainstem responses (ABRs) of adult WT, heterozygous Xirp2-null, and homozygous Xirp2-null mice were recorded from ages 4 to 12 weeks. Mice were anesthetized with a single intraperitoneal injection of $100 \mathrm{mg} / \mathrm{kg}$ ketamine hydrochloride (Fort Dodge Animal Health) and $10 \mathrm{mg} / \mathrm{kg}$ xylazine hydrochloride (Lloyd Laboratories). All ABRs were performed in a sound-attenuating booth (Med-Associates), and mice were kept on a Deltaphase isothermal heating pad (Braintree Scientific) to maintain body temperature. ABR recording equipment was purchased from Intelligent Hearing Systems. Recordings were captured by subdermal needle electrodes (FE-7; Grass Technologies). The noninverting electrode was placed at the vertex of the midline, the inverting electrode over the mastoid of the right ear, and the ground electrode on the upper thigh. Stimulus tones (pure tones) were presented at a rate of $21.1 / \mathrm{s}$ through a high-frequency transducer (Intelligent Hearing Systems). Responses were filtered at $300-3000 \mathrm{~Hz}$ and threshold levels were determined from 1024 stimulus presentations at 8 , $11.3,16,22.4$, and $32 \mathrm{kHz}$. Stimulus intensity was decreased in 5-10 dB steps until a response waveform could no longer be identified. Stimulus intensity was then increased in $5 \mathrm{~dB}$ steps until a waveform could again be identified. If a waveform could not be identified at the maximum output of the transducer, a value of $5 \mathrm{~dB}$ was added to the maximum output as the threshold.

\section{Results}

\section{A short form of XIRP2 is an abundant component of the hair bundle}

We recently used a peptide mass spectrometry-based strategy to characterize the hair bundle proteome of chick vestibular organs (Shin et al., 2007, 2013), and identified an uncharacterized protein annotated as ENSGALP00000017765, which corresponded to the gene ENSGALG00000010933 on chromosome 7 (Fig. 1A). This protein was abundant in chick hair bundles; with $\sim 4500$ molecules per stereocilium, it is present at $\sim 1 \%$ of actin's concentration (Shin et al., 2013). Although sequence homology analysis initially failed to identify a mammalian ortholog, analysis of genetic synteny showed that ENSGALG00000010933 is the chick equivalent of the mammalian Xirp2 gene (Fig. 1B). ENSGALP00000017765 and mammalian XIRP2 show high sequence homology only in their LIM domains (Fig. 1C), however, and exhibit only weak homology in the remainder of their sequence. Notably, chick XIRP2 lacks Xin repeats, the signature domain of mammalian XIRP2. Confirming the hair bundle proteomic analysis, chick XIRP2 immunoreactivity was specifically localized in chick utricle stereocilia (Fig. 1D). 
A

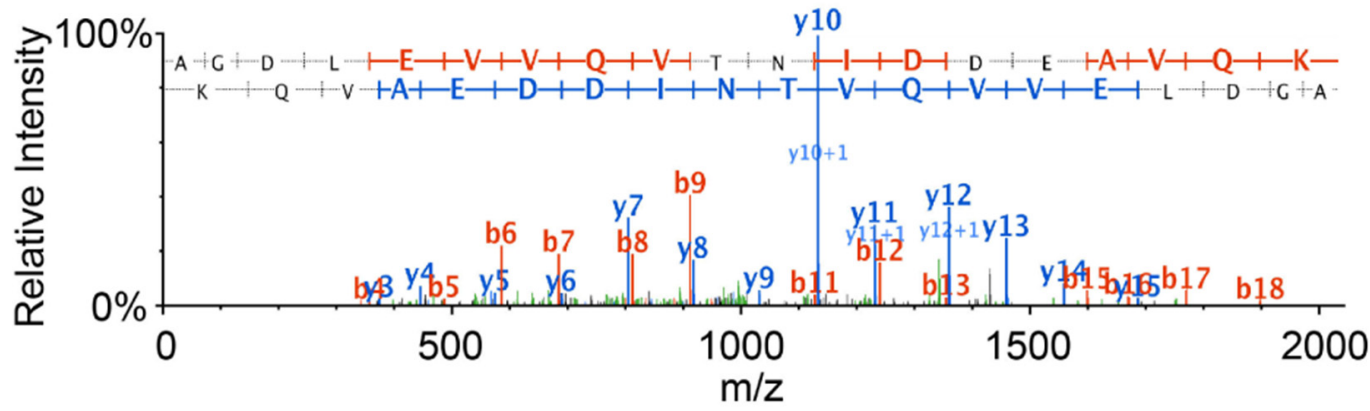

B
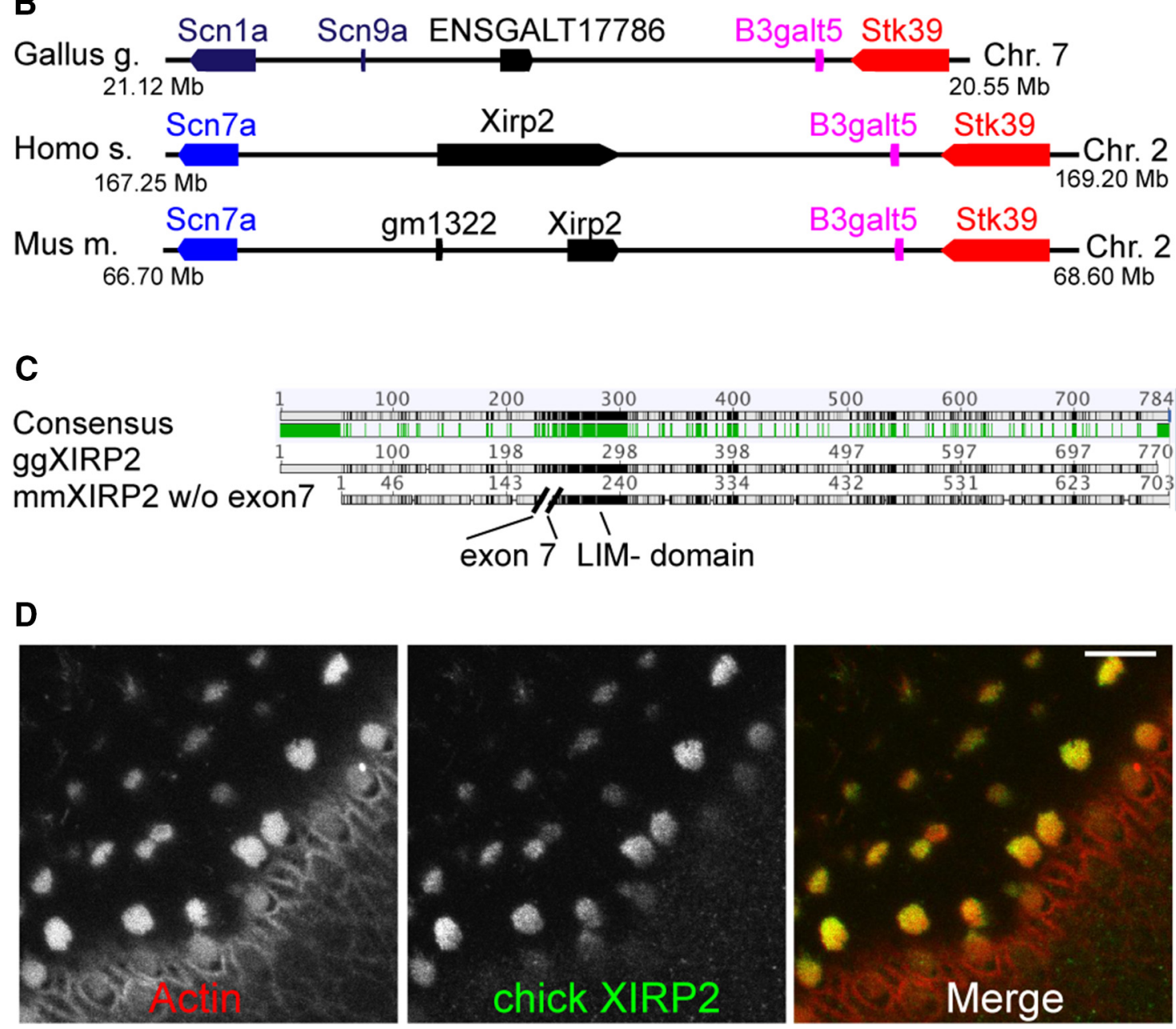

Figure 1. XIRP2 is an evolutionarily conserved component of the hair cell stereocilia bundle. A, MS/MS spectrum of a representative peptide of ENSGALP00000017765, identified by LC-MS/MS on isolated chick hair bundles. $\boldsymbol{B}$, Analysis of synteny identified chicken ENSGALP00000017765 as an ortholog of human and mouseXIRP2. C, Strong sequence homology between chick and mouse XIRP2 is restricted to the LIM domain. To allow effective alignment, and for better visualization, the Xin repeat-containing exon 7, present in the "long XIRP2" isoform in the mouse, was excluded from this alignment. $\boldsymbol{D}$, Immunocytochemical analysis of chick XIRP2 confirmed its presence in chicken hair cell stereocilia. Scale bar, $5 \mu \mathrm{m}$.

In the mouse, the Xirp2 gene extends over $>340 \mathrm{~kb}$ on chromosome 2 (Fig. 2A), and is expressed in multiple poorly characterized splice forms. The isoforms can be grouped into long and short XIRP2 isoforms, and the most striking difference is the differential usage of exon 7, which contains all of the Xin repeats. Because the XIRP2 expressed in chick hair bundles lacks Xin repeats, we set out to determine whether a similar isoform, lacking Xin repeats, might be localized in mouse hair cells. Examination of GenBank sequences for mouse Xirp2 and human XIRP2 transcripts revealed several entries (e.g., "Xeplin" variants ABO69241, ABO69242, ABO69243, and $\mathrm{ABO} 69244$ ) that not only lacked the large exon 7 (and thus the Xin repeats), but also appeared to have additional $5^{\prime}$ exons. While none of the mouse Xirp2 sequences included exons from Gm1322, which is immediately upstream of Xirp2, several human XIRP2 splice forms included exons equivalent to Gm1322 (e.g., NP_001073278 and NP_001186072). In both species, transcripts that lacked exon 7 exhibited an altered reading frame in exon 8 ; while long forms of Xirp2 have a translation stop site in exon 8, the open reading frame in forms lacking exon 7 extends through exon 8 , nearly to the end of exon 9 (Fig. 2A, see highlighted ATG and STOP). 
A

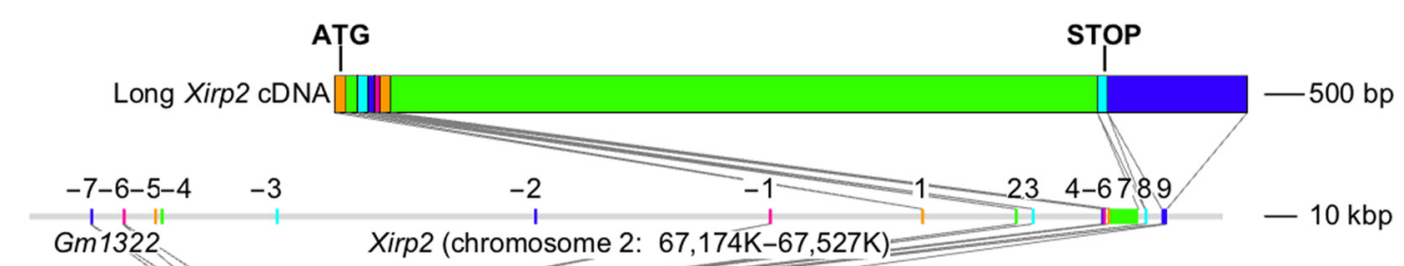

Short Xirp2 cDNA

B
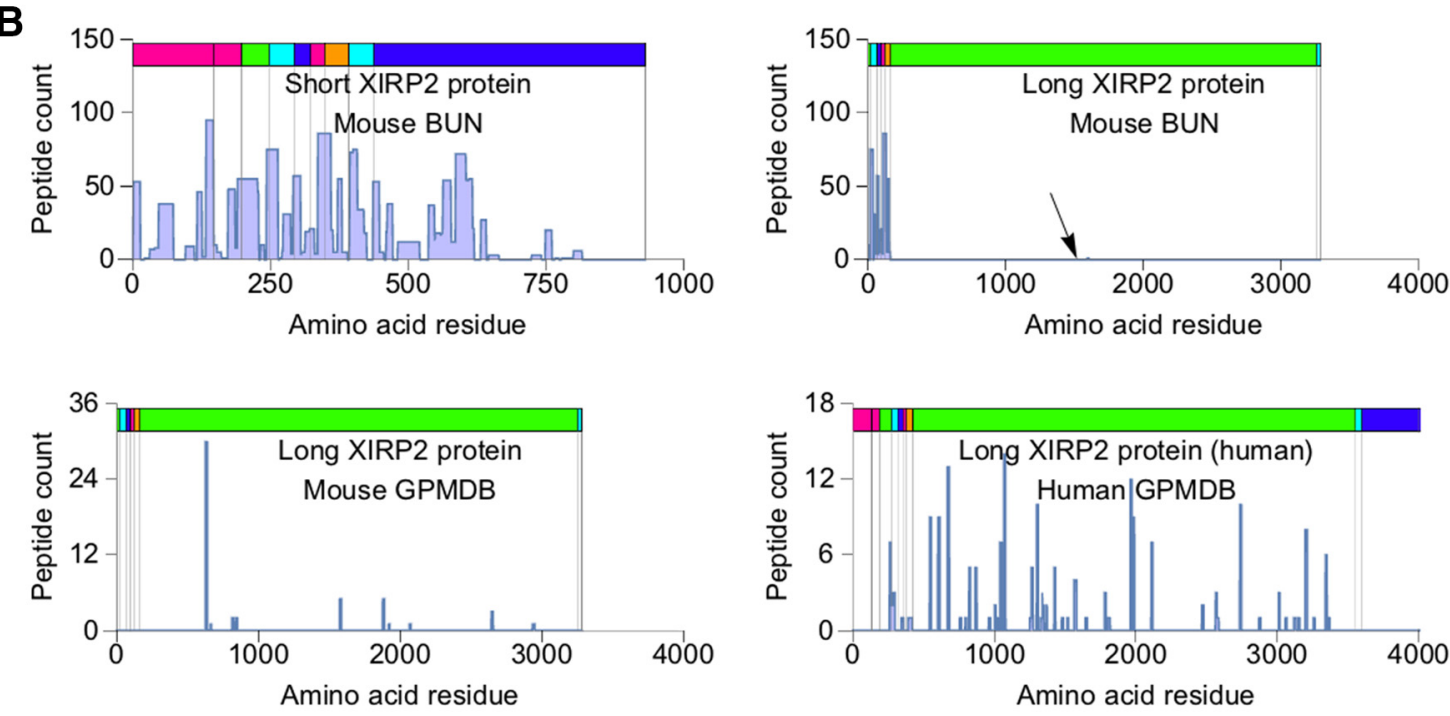

C
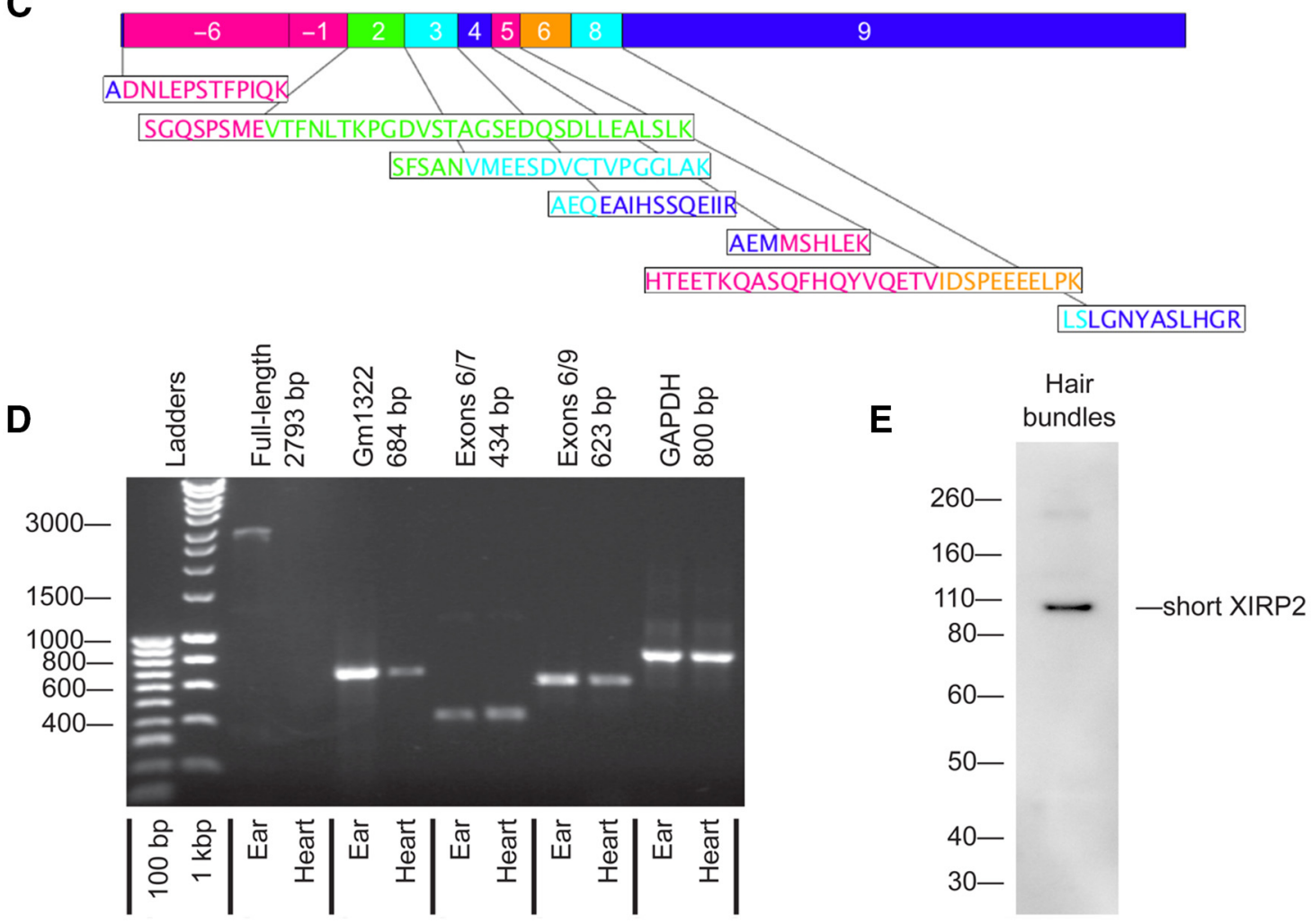
From mouse inner ear cDNA, we amplified an Xirp2 transcript (reported as KM273012 in GenBank) that contained the two exons annotated as Gm1322 in the present mouse database and five additional $5^{\prime}$ exons not found in the canonical form of Xirp2; on the 3' end, this transcript possessed exons 2-6 of Xirp2, lacked the large exon 7, but included the large open reading frame extending through exons 8 and 9 . We defined this splice form as "short XIRP2," distinguishing it from forms including exon 7 ("long XIRP2"). Transcript structures are indicated in Figure 2A. Note that these two proteins differ substantially in their amino acid structure; $<10 \%$ of long XIRP2 is found in the short form, while only $\sim 25 \%$ of short XIRP2 is found in the long form.

To determine which XIRP2 protein isoform is targeted to the hair bundle, we performed peptide MS analysis on purified mouse utricle bundles. Given sufficient peptide coverage, a protein's exon usage and isoform representation can be inferred. As illustrated in Figure $2 B$, upper right, the vast majority of XIRP2specific peptides mapped to the $\mathrm{N}$ terminus of the long XIRP2 isoform, and spared the large Xin repeat-containing region encoded by exon 7 . This result was unlikely to have been caused by failed detection of peptides encoded by exon 7 , as such peptides were readily detected in human and mouse XIRP2 data from the GPMDB (Fig. 2B, bottom, left and right). In contrast, peptides mapped to all exons of short XIRP2, including exons only included and translated in the short form (exons $-7,-6$, and -1 , the C-terminal half of exon 8, and exon 9; Fig. 2B, upper left). These results establish that the bundle expresses the short XIRP2 splice form, and show that mouse Gm1322 is part of Xirp2. Convincingly demonstrating the identity of the bundle-specific isoform on the protein level, peptides that span adjacent exons were found for almost all exon-exon transitions, providing indisputable evidence for the proposed splice pattern (Fig. 2C).

Next, we compared the expression of the short and the long Xirp2 transcripts in the ear and the heart, by conducting RT-PCR (Fig. 2D). A PCR product corresponding to full-length short XIRP2 was detected in the ear, but was conspicuously absent from the heart. In contrast, PCR products spanning from exon -7 to 2 and from exon 6 to 7 , as well as from exon 6 to 9 , were

\section{$\leftarrow$}

Figure 2. Peptide MS-based identification of hair bundle-specific XIRP2 isoforms. A, Schematic depiction of the Xirp2 locus on chromosome 2 of the mouse genome. The two major XIRP2 isoforms are illustrated, with the exon usage highlighted by connecting lines to the genomic track: the canonical, long XIRP2 transcript is depicted above (lacks upstream exons -1 to -7 , includes exon 7, and the frame of exon 8 encodes a stop codon, preventing translation of exon 9). The short Xirp2 transcript is shown below (including exons $-7,-6$ and -1 , not present in long Xirp2; exons 1 and 7 are not present, but the frame of exon 8 permits translation through exon 9). $\boldsymbol{B}$, Top left, Peptides from isolated utricular bundles that map to short XIRP2. Peptides that correspond to all exons predicted from transcript KM273012 (submitted to GenBank) were detected in the bundle data. Top right, Peptides isolated from utricular hair bundles that map to long XIRP2. Most peptides map to the N terminus of the long XIRP2 isoform; exon 7 has very few mapped peptides (arrow), suggesting that the long isoform is not present in the hair bundle. Bottom, Mouse peptides from GPMDB map to long XIRP2, including exon 7, and human peptides from GPMDB map to long XIRP2, including exon 7. C, Peptides detected in purified utricle bundles that span neighboring exons of short XIRP2. D, RT-PCR-based analysis of Xirp2 exon usage in heart and inner ear tissue: the transcript coding for the full-length short XIRP2 isoform was detected in inner ear, but absent in heart CDNA. The newly discovered 5' exons (represented by a PCR fragment spanning exon -7 to exon 2) were nevertheless expressed in the heart, albeit at significantly lower levels compared with the ear. A PCR product indicative of the transition from exon 6 to exon 7 was detected in both ear and heart, but was stronger in the latter. A product indicative of the transition from exon 6 to 9 was detected in both ear and heart, but stronger in the former. $\boldsymbol{E}$, Western blot analysis of hair bundles isolated from the mouse utricle (using the exon -6 -specific antibody), detects a band with the mass of $\sim 105 \mathrm{kDa}$, consistent with the predicted mass of short XIRP2 (104.5 kDa). detected in both ear and heart, albeit with differences in expression levels. The transcript analysis suggests tissue-specific differences in XIRP2 splice form expression. While the long form is also expressed, the inner ear predominantly expresses a short isoform that includes exons $-7,-6$ and -1 (former Gm1322), and exon 9, but lacks exon 7. This short isoform is not expressed in the heart, but other isoforms using the newly identified $5^{\prime}$ exons are expressed. Understanding XIRP2's function in the heart thus needs to take into consideration these upstream exons. Finally, Western blot analysis of hair bundles isolated from the mouse utricle (using an exon -6-specific antibody), produced a band consistent with the predicted mass of short XIRP2 $(\sim 105$ $\mathrm{kDa}$ ), providing further evidence for the presence of the short XIRP2 isoform in the hair bundle (Fig. 2E).

\section{Spatiotemporal expression of XIRP2 in the mouse inner ear}

We next examined the spatiotemporal expression of XIRP2 in the mouse inner ear. Immunocytochemistry analysis using the XIRP2 D-18 antibody demonstrated that XIRP2 is specifically expressed in auditory and vestibular hair cells, with its localization restricted to the stereocilia and apical portion of the hair cell. Cochlear XIRP2 expression starts at E18, coinciding with the emergence of hair bundles, and continues into adulthood (Fig. $3 A$ ). Likewise, XIRP2 is abundant during development of mouse vestibular bundles (Fig. $3 B, C$ ). As can be seen in Figure $3 B$, XIRP2 immunoreactivity in P30 utricle stereocilia is heterogeneous, with some stereocilia exhibiting strong XIRP2 immunoreactivity while other stereocilia in the same bundle display weaker signals; this localization could reflect true distribution of the XIRP2 protein or could result from epitope masking in mature stereocilia. Indeed, XIRP2 immunocytochemistry was highly dependent on fixation time; formaldehyde treatment of $>20 \mathrm{~min}$ abolished staining in adult cochlear outer hair cell bundles and a subset of vestibular hair bundles.

\section{XIRP2 is localized at actin-membrane interface in stereocilia}

To provide a more precise localization of XIRP2, we performed immunocytochemistry (using two antibodies recognizing distinct peptide epitopes) on rat inner hair cell stereocilia; because they are considerably thicker than those of mouse, they allow improved spatial resolution. Strikingly, XIRP2 immunoreactivity was restricted to the interface between the F-actin core and the stereocilia membrane (Fig. 4A,B). Since limited antibody penetration into the actin core in the whole-mount preparations might have caused this phenomenon, we performed postembedding immunogold TEM studies on ultrathin sections. As shown in Figure 4C, XIRP2-associated gold particles were localized preferentially near the stereocilia membrane (black arrows). This localization was confirmed by a spatial distribution analysis of $>70$ immunogold particles (Fig. 4C, $D, F$ ). In control experiments, immunogold particles associated with a pan-espin antibody did not display preferential localization at the periphery of the stereocilium, but were more evenly distributed over the entire cross section (Fig. 4E, F).

\section{XIRP2 localizes to adherens junctions}

As demonstrated in Figure 3, XIRP2 immunoreactivity was not restricted to the hair bundle. In utricle hair cells, strong XIRP2 immunoreactivity is also evident in the cuticular plate and the apical cell junction (Fig. 3C). In the cochlea, XIRP2 was initially (up to $\sim \mathrm{P} 4$ ) restricted to the bundle, but spread to the pericuticular region in the mature hair cell (Fig. 3A). In cardiomyocytes, XIRP2 localizes to the intercalated disk (Q. Wang et al., 2012), 

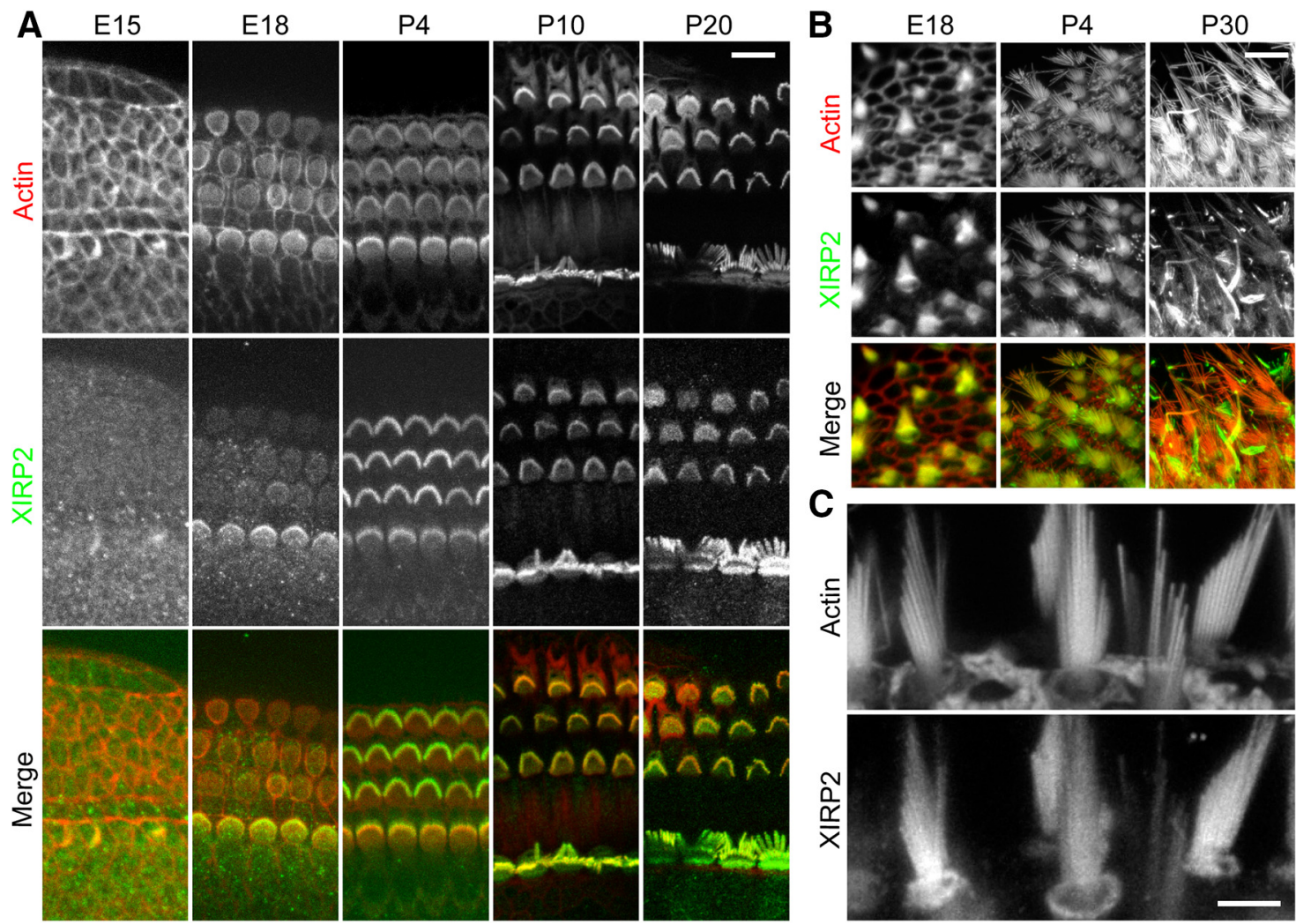

Figure 3. XIRP2 is expressed in mouse cochlear and vestibular hair cells. A, Immunocytochemical analysis of XIRP2 expression in the mouse cochlea of various ages (using the XIRP2 D-18 antibody). Onset of XIRP2 expression in hair cells begins at E18, coinciding with the emergence of the hair bundle. XIRP2 is localized to the apical region of the hair cell and bundles in both the developing and mature mouse cochlea. Scale bar, $10 \mu \mathrm{m} . \boldsymbol{B}$, XIRP2 immunoreactivity in the vestibular system parallels the expression pattern seen in the cochlea, with onset at E18, specifically in the apical regions of hair cells and stereocilia, with continued expression into adulthood. Scale bar, $10 \mu \mathrm{m}$. C, XIRP2 immunoreactivity in the mouse vestibular hair bundle, P4. Scale bar, $5 \mu \mathrm{m}$.
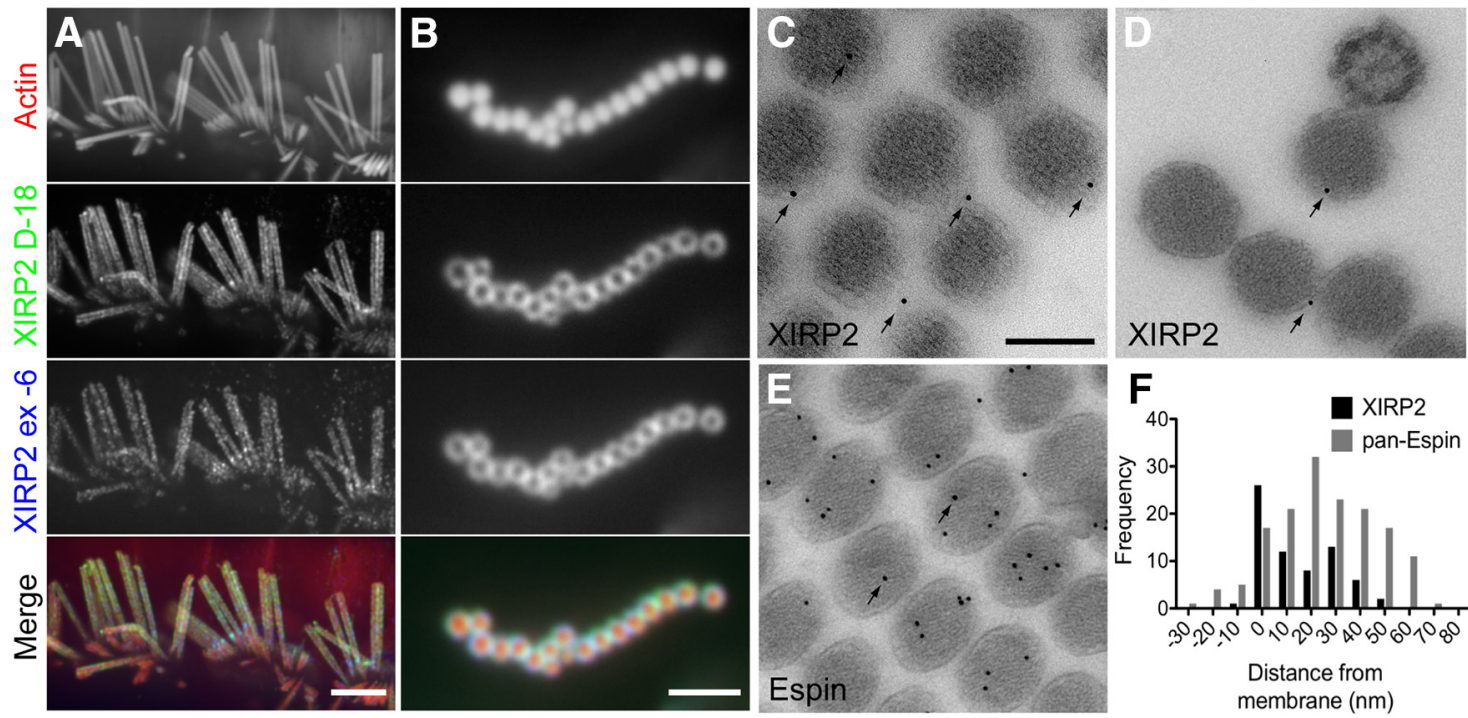

Figure 4. Subcellular localization of XIRP2 in stereociliar bundles. $A, B$, XIRP2 immunocytochemistry performed on rat cochlear inner hair cells. Triple labeling with phalloidin, D-18 antibody, and XIRP2 exon -6-specific antibody. Immunoreactivity from both XIRP2 antibodies is localized at the periphery of the F-actin core. Peripheral localization is more apparent in cross sections ( $\boldsymbol{B}$ ). Scale bars: $A, 5 \mu \mathrm{m} ; \boldsymbol{B}, 2 \mu \mathrm{m} . \boldsymbol{C}, \boldsymbol{D}$, Postembedding immunogold transmission electron microscopy on ultrathin sections of freeze-substituted, plastic embedded samples indicate that anti-XIRP2-directed immunogold particles are localized between the stereocilia membrane and actin core. $\boldsymbol{E}$, Espin immunogold labeling is evenly distributed across the stereocilia actin core. Scale bars: $\mathbf{C}-\boldsymbol{E}, 200 \mathrm{~nm}$. $F$, Quantification of immunogold labeling.

which is a site of mechanical and electrical coupling between neighboring cardiomyocytes and thus can be considered analogous to the hair cell/supporting cell junction. Since XIRP2 binds to $\alpha$-actinin (Huang et al., 2006), which is a component of adhe- rens junctions, we hypothesized that XIRP2 also localizes to adherens junctions of hair cells. We performed triple-labeling experiments on P3 rat utricle whole mounts, with antibodies specific for XIRP2 (D-18), $\alpha$-actinin, and non-muscle myosin 
IIC (NMIIC), the latter two known components of the adherens junctions. As demonstrated in Figure 5, all three proteins localized at periodic loci along the apical hair cell junction. Detailed analysis of the intensity profile (region of interest is outlined by the dotted path in Fig. 5D) demonstrated that XIRP2-positive foci colocalized with NMIIC, but displayed a nonoverlapping, alternating pattern with $\alpha$-actininpositive foci along the junctional line (Fig. 5E).

\section{Isoform-specific expression and} localization of XIRP2 in the hair cell RT-PCR analysis with whole inner ear cDNA suggested that hair cells, in addition to the short form, also express the long XIRP2 isoform (Fig. 2D). Furthermore, while mass spectrometry analysis showed that stereocilia contain nearly exclusively short XIRP2, a few peptides mapping to exon 7 were nevertheless identified (indicated by the arrow in Fig. $2 B$, upper right). We hypothesized that long XIRP2 targeted to the pericuticular region, which occasionally contaminates purified hair bundles (Shin et al., 2007). We therefore set out to determine the subcellular localization of XIRP2 splice forms, by performing immunocytochemistry analysis using antibodies that exclusively detect the short (exon 9-specific) or long (exon 7-specific) isoforms. To validate antibody specificities, we performed immunolabeling with all four XIRP2 antibodies used in this study, on heterologous LLC-PK11-CL4 (CL4) cells expressing GFP-tagged short XIRP2. The immunoreactivities of the D-18, exon -6 and exon 9 antibodies colocalized with the short XIRP2-GFP signal, while the exon 7 antibody, directed against an epitope not present in the short XIRP2 isoform, exhibited no staining (Fig. 6A). We do not have a positive control for the exon 7 antibody because we were not able to clone and express the long isoform $(\sim 350 \mathrm{kDa})$ in heterologous cells. As illustrated in Figure $6 B$, the exon 9-specific antibody exclusively stained stereocilia in cochlear and vestibular hair cells. Immunoreactiv-

ity was excluded from the underlying apical portion of the hair cell, which showed robust staining with the D-18 antibody (white arrow). These results confirm that the short XIRP2 isoform is stereocilia specific. In contrast, an antibody specific for exon 7, which recognizes the long XIRP2 isoform, failed to label stereocilia in utricular hair cells; instead it labeled the pericuticular necklace region (Fig. 6 C). The long XIRP2 isoform was absent in early postnatal cochlear hair cells, even in the pericuticular region (Fig. 6C). In mature cochlear hair cells, some localization in the cuticular plate was evident (data not shown). In summary, the immunocytochemistry analysis corroborates our mass spec-

E
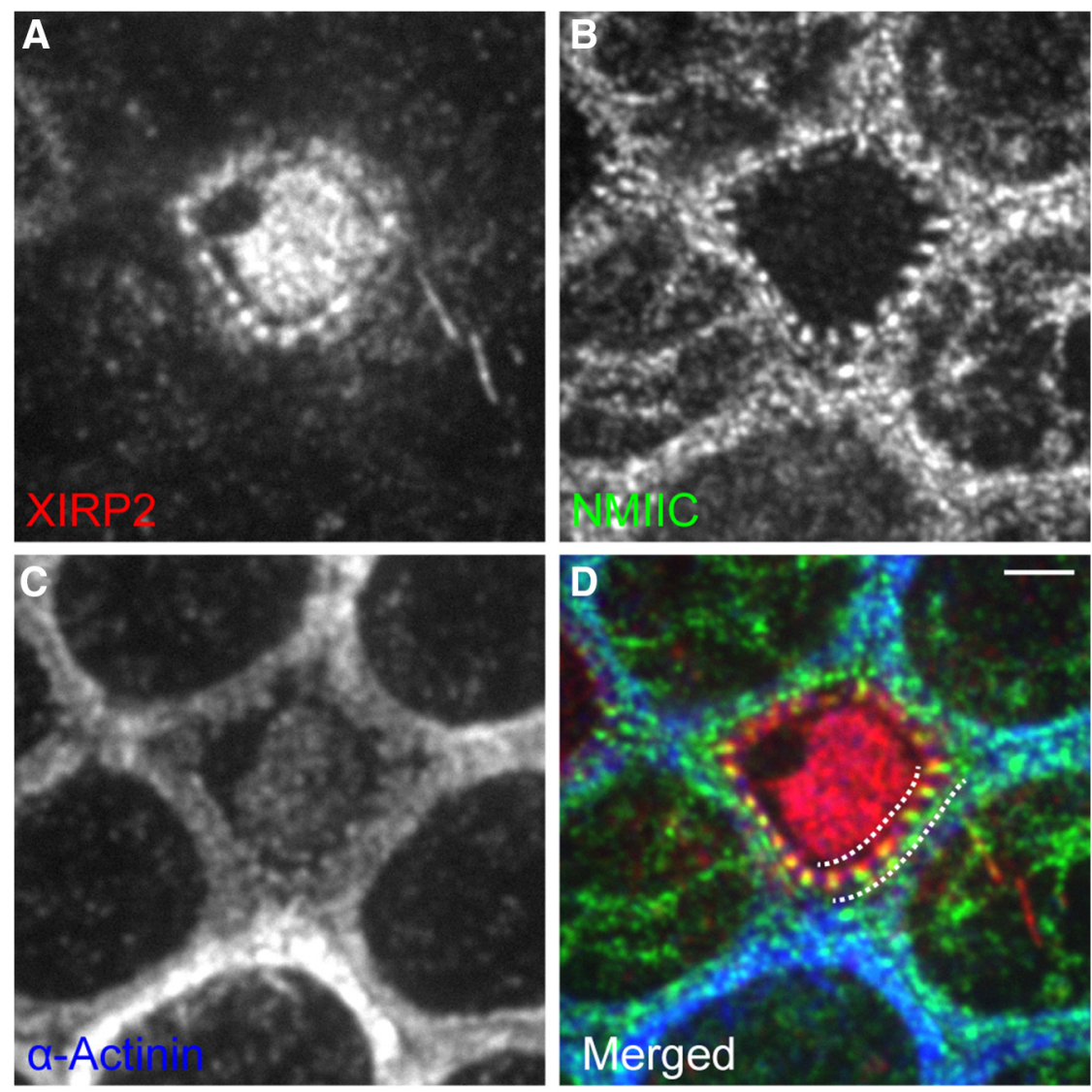

Figure 5. Subcellular localization of XIRP2 in the pericuticular region of hair cells. A-D, Triple labeling for XIRP2 (D-18 antibody, red in merged image), $\alpha$-actinin (blue), and NMIIC (green) in P3 rat utricle. Scale bar, $2 \mu \mathrm{m}$. $\boldsymbol{E}$, Intensity profile analysis (region of interest is outlined by the dotted path in D) demonstrating that XIRP2-positive foci colocalized with NMIIC, but alternated with $\alpha$-actinin-immunopositive foci along the cell junctional line.

trometry analysis, which together demonstrate that the sensory hair bundle harbors the short XIRP2 isoform, while the pericuticular plate and the apical cell junction use the long, Xin repeatcontaining XIRP2 isoform.

The short, bundle-specific XIRP2 isoform localizes to actinrich extensions in cultured cells

Next, we characterized the subcellular localization of short XIRP2 by expressing GFP or Myc-tagged versions of this isoform in CL4 (Zheng et al., 2010) and HEK293 cell lines. While GFP alone diffused throughout the cytoplasm (Fig. 7A), GFP-tagged 
A GFP short
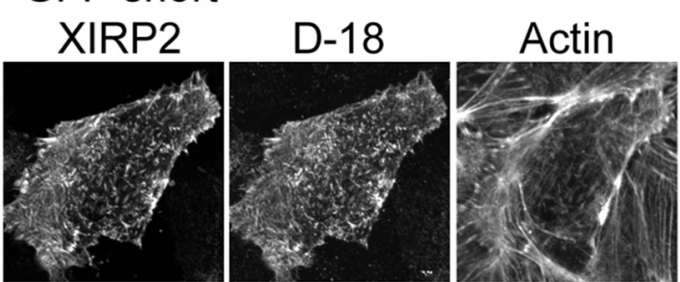

GFP short

GFP short XIRP2
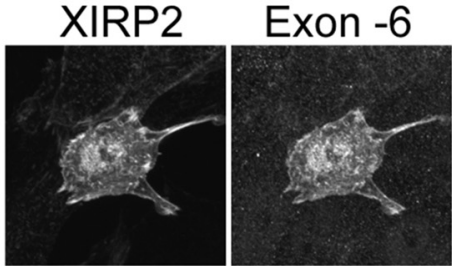

Actin
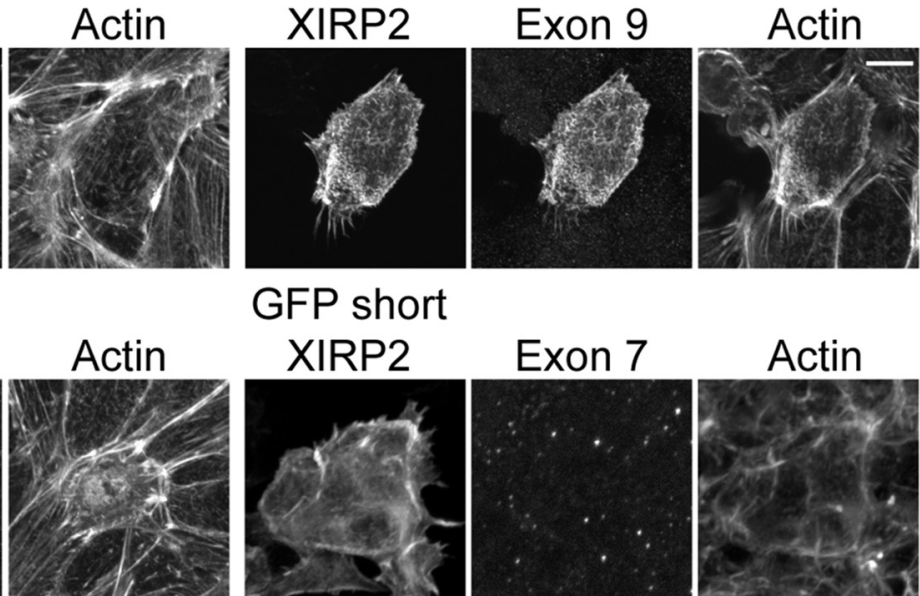

B

Actin XIRP2 D-18

GFP short
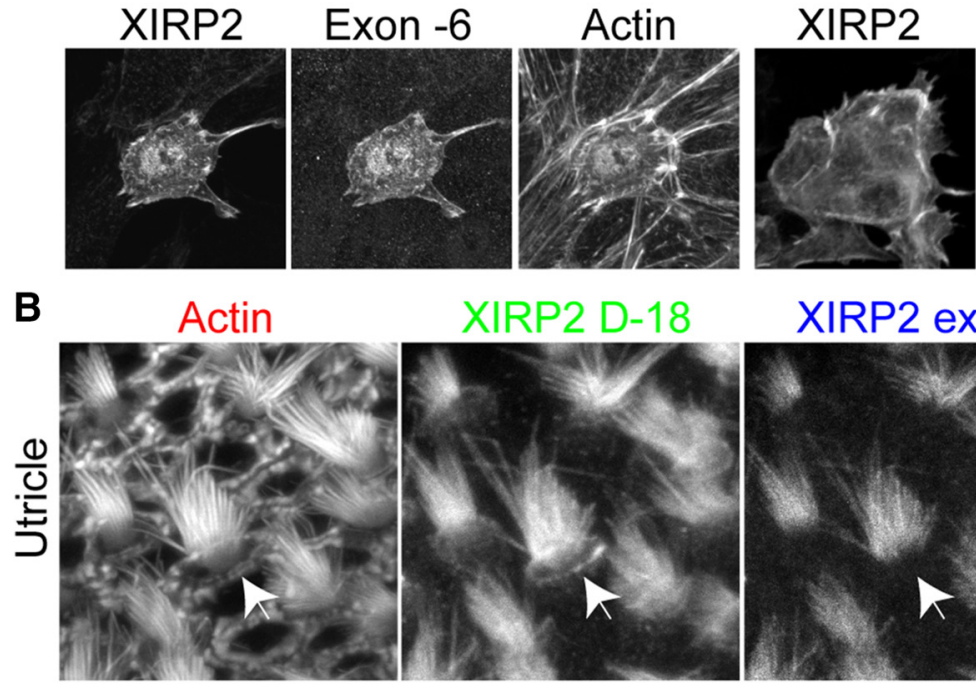

Exon 7
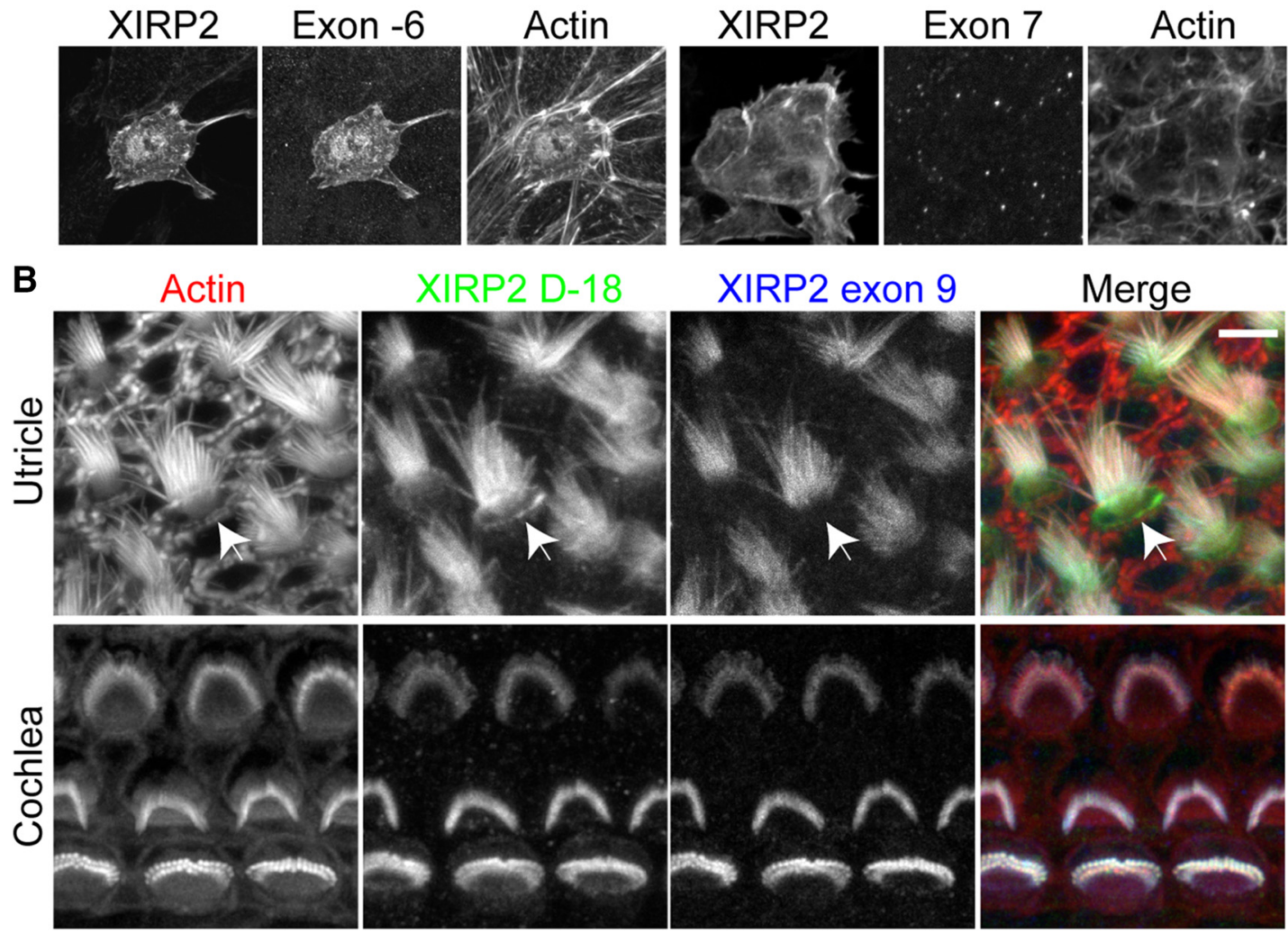

C
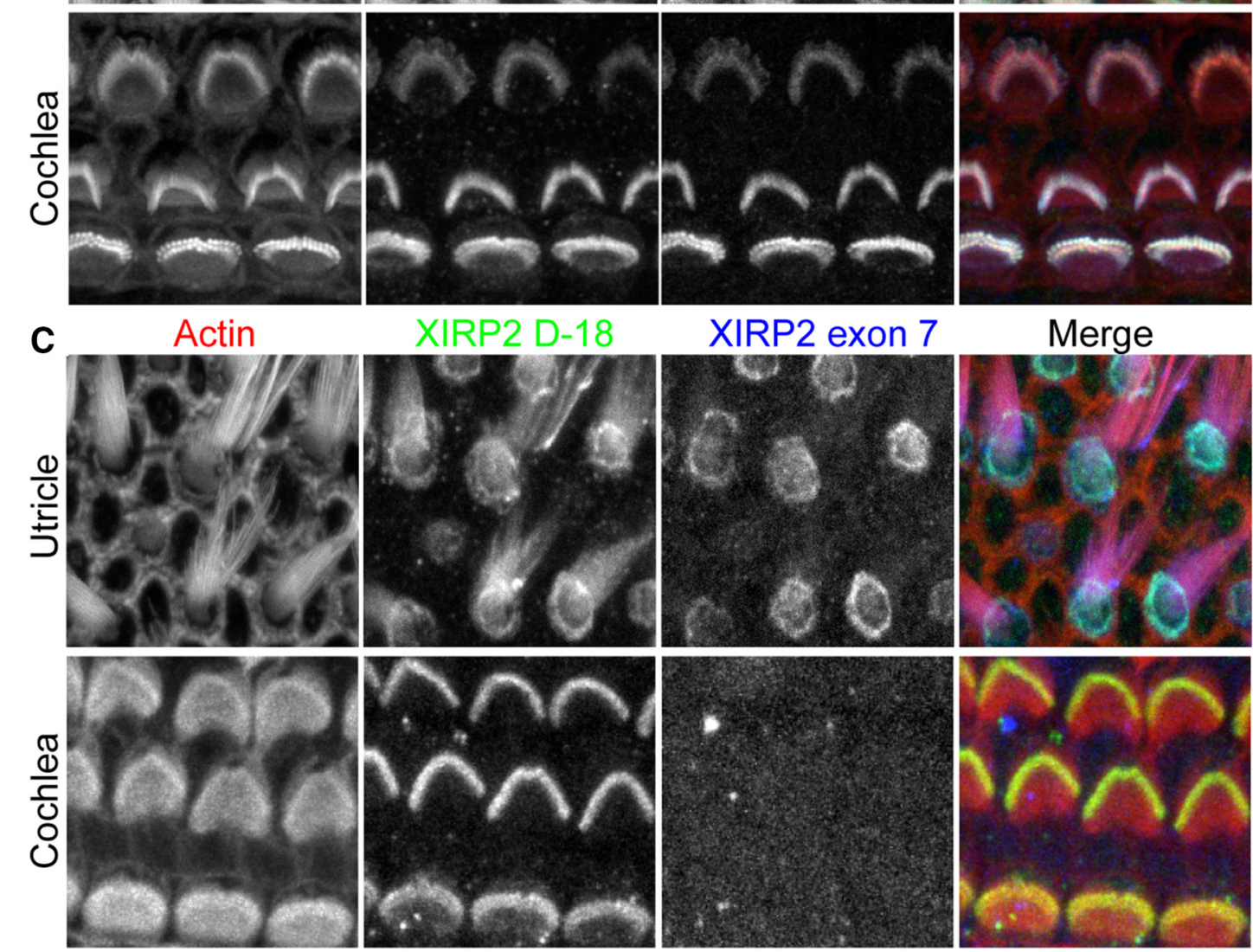

\section{Merge}
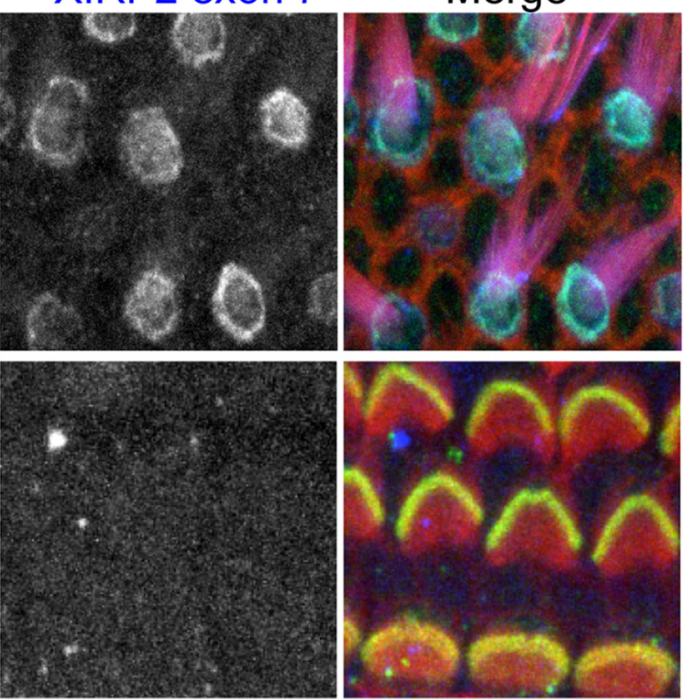

Figure 6. Isoform-specific XIRP2 immunocytochemistry. A, Validation of isoform-specific XIRP2 antibodies. Immunocytochemistry was performed on CL4 cells expressing GFP-tagged short XIRP2. The immunoreactivities of the D-18, exon -6, and exon 9 antibodies colocalized with the XIRP2-GFP signal, while the exon 7 antibody, directed against an epitope not present in the short XIRP2 isoform, exhibited no staining. Scale bar, $5 \mu \mathrm{m}$. B, D-18 and exon 9-specific antibodies revealed distinct expression patterns in P4 mouse utricular and cochlear hair cells. D-18 immunoreactivity is found both in the pericuticular region and stereocilia of utricular hair cells. In contrast, immunoreactivity from the exon 9-specific short form is seen in bundles but is excluded from the pericuticular necklace (arrows). C, Labeling with an exon 7-specific antibody showed immunoreactivity limited to the cuticular plates of utricular hair cells. No immunoreactivity was observed in cochlear hair cells in P4 mice. Scale bar, $5 \mu \mathrm{m}$. 

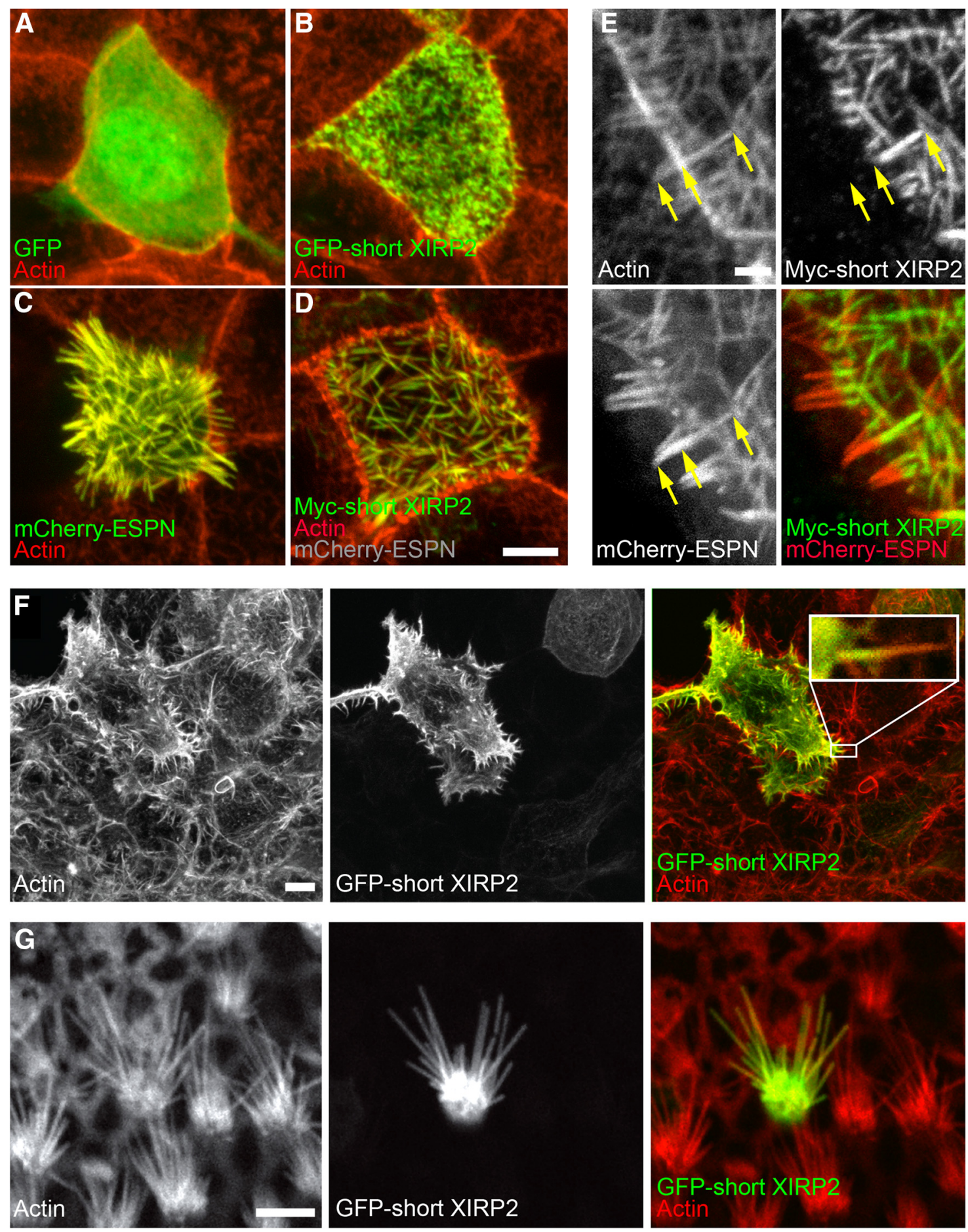

Figure 7. The short, bundle-specificXIRP2 isoform localizes to actin-rich extensions in cultured cells. $\boldsymbol{A}$, GFP transfected into $C L 4$ cells was present throughout the cytoplasm. $\boldsymbol{B}$, Short XIRP2 tagged with GFP colocalized with F-actin-rich microvilli in CL4 cells. C, Espin-elongated CL4 microvilli. D, Short XIRP2-GFP localized to espin-rich microvilli (mCherry-ESPN in gray indicates that it is coexpressed, but not displayed in the merged image). Scale bar, $5 \mu \mathrm{m}$. E, XIRP2 immunoreactivity is restricted to the rootlet of the microvilli, however, despite espin expression throughout. Scale bar, $2 \mu \mathrm{m}$. $\boldsymbol{F}$, Short XIRP2-GFP colocalizes with actin-rich structures and is targeted to the filopodia in HEK293 cells. Short XIRP2-GFP is excluded from the distal parts of the filopodial extensions (inset). G, Biolistic (gene gun) transfection of short XIRP2-GFP into P1 mouse utricular hair cells. Short XIRP2-GFP is targeted specifically to the stereocilia. Scale bars and inset width: $\boldsymbol{F}, \mathbf{G}, 5 \mu \mathrm{m}$.

short XIRP2 colocalized with F-actin at the membrane and microvilli in CL4 cells (Fig. 7B). ESPN expression produces elongated microvilli in CL4 cells (Sekerková et al., 2011; Fig. 7C). When Myc-tagged short XIRP2 was coexpressed with mCherrytagged ESPN, XIRP2 colocalized with F-actin in microvilli (Fig. $7 D)$. However, XIRP2 was not present in distal regions of the microvilli, but was restricted to the intracellular, rootlet portion of the microvilli (Fig. 7E). In HEK293 cells, the short XIRP2 variant extended further into the actin-rich extensions, although the most distal portion was still free of XIRP2 (Fig. $7 F$ ). Exclusion of XIRP2 from the distal part of the microvilli and other actinrich extensions contrasts with its uniform stereociliar localization. To directly determine where short XIRP2 localizes in stereocilia, we introduced GFP-tagged short XIRP2 into mouse 
A
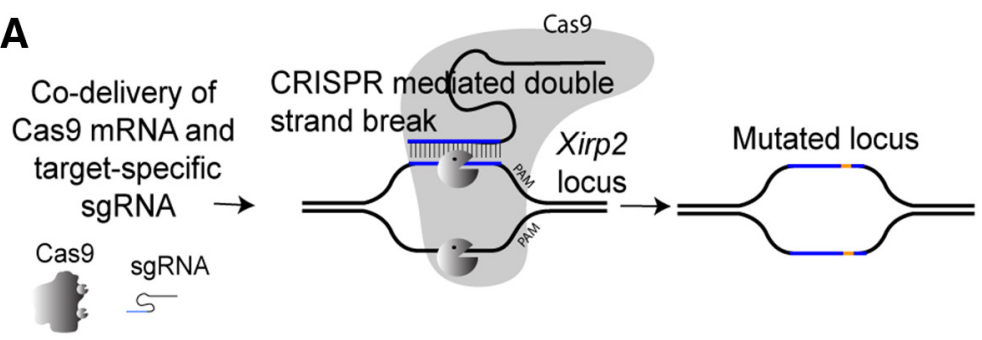

B

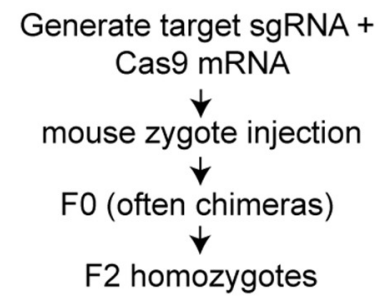

c

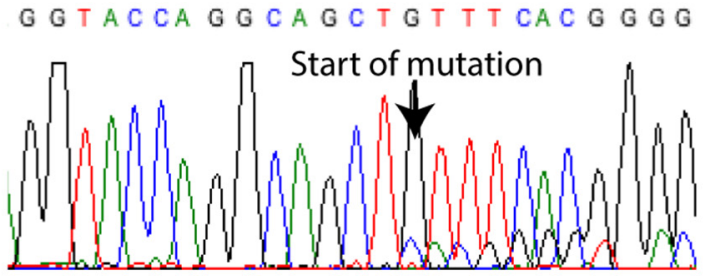

D

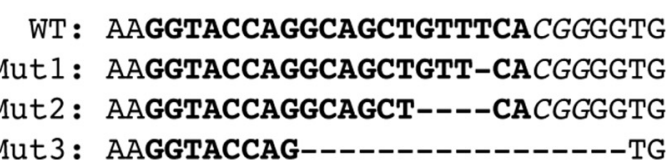

E

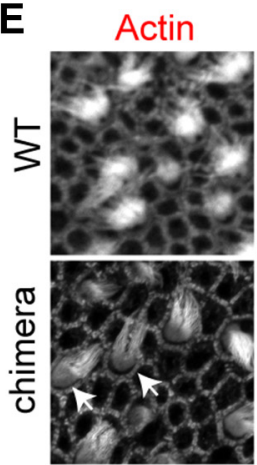

XIRP2

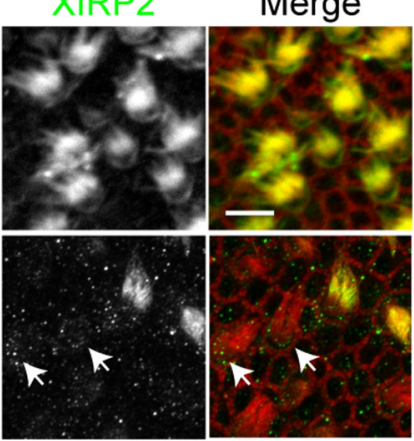

Figure 8. CRISPR/Cas9-mediated generation of Xirp2-null mice. $\boldsymbol{A}$, CRISPR/Cas9 gene-editing technology principles: mRNA encoding the bacterial endonuclease Cas9 is co-injected along with guide RNAs (sgRNA). The sgRNA guides (as9 to the targeted region of the Xirp2 gene, where it then cleaves both strands of DNA; the resulting double-strand break is repaired by nonhomologous end joining, which can cause deleterious insertions and deletions. B, Strategy for developing null mouse lines. C, Typical sequencing chromatogram from a CRISPR/Cas9-generated Xirp2 mutant mouse. The sequence becomes scrambled at the start of the mutated site, where NHEJ has introduced a 4 bp deletion (arrow). D, Three frameshift-causing mutations (1, 4, and 17 bp deletions) of $X$ irp2 2 were chosen for further analysis. $\boldsymbol{E}$, Analysis of the utricle from a mouse embryo (E18) with a detectable null mutation in the Xirp2 gene revealed the heterogeneous loss of XIRP2 expression in a subset of hair cell stereocilia (arrows), suggesting a chimeric genotype for this mouse. Scale bar, $10 \mu \mathrm{m}$.

utricle hair cells using biolistic transfection. Short XIRP2 was targeted to the entire length of the stereocilia (Fig. $7 G$ ).

\section{CRISPR/Cas9-mediated ablation of XIRP2 expression in the mouse}

To investigate the relevance of XIRP2 for hearing, we used CRISPR/Cas9 to disrupt the Xirp2 gene in the mouse genome. The CRISPR/Cas9 system is an adaptive immune system in bacteria, providing defense against invading viral DNA (Barrangou et al., 2007; Brouns et al., 2008; Horvath and Barrangou, 2010; Terns and Terns, 2011). Recently, the CRISPR/Cas9 system from S. pyogenes has been adapted for targeted genome engineering in eukaryotic cells (Jinek et al., 2012; Cong et al., 2013; Hwang et al., 2013; Mali et al., 2013). As illustrated in Figure 8A, successful targeting is dependent on a chimeric (single) guide RNA (sgRNA) containing a $20 \mathrm{nt}$ target sequence of choice, and the endonuclease Cas9. Any 20 bp sequence followed by a so-called PAM, which in S. pyogenes Cas9 is NGG, can be targeted. The sgRNA functions to guide Cas9 to the target sequence, where it will create a double-strand break. The preferred method for double-strand break repair is the inherently error-prone nonhomologous end joining (NHEJ), which produces insertions and deletions (indels); depending on their size and location, the indels can cause frameshift mutations that produce a null phenotype. We selected a CRISPR-amenable target on exon 2 of the mouse Xirp2 gene, and performed in vitro transcription to generate the mRNA for the endonuclease Cas 9 and the sgRNA. Pronuclear injections of the RNA were performed and zygotes were implanted into pseudopregnant foster mothers. A summary of the experimental procedure is illustrated in Figure $8 B$.

Similar to published mutagenesis rates (H. Wang et al., 2013), we detected mutations in $25-50 \%$ of the embryos, some of which produced a frameshift (exemplary 1, 4, and 17 bp deletions are shown in Fig. $8 C, D$ ). In the F0 generation, many embryos were chimeric for the mutation, indicating mutational targeting at a multicellular embryo stage; chimerism was especially evident in immunocytochemistry analysis. At E18, all WT vestibular hair cells express XIRP2 (Fig. 8E, top); in contrast, a subset of hair cells in mutant embryos completely lacked XIRP2 immunoreactivity (Fig. 8E, arrows), consistent with a bi-allelic deletion of the Xirp2 gene in those cells. F0 mice with deleterious $1 \mathrm{bp}, 4 \mathrm{bp}$, or $17 \mathrm{bp}$ deletions in exon 2 (Fig. 8D) were bred for two generations, producing three mouse strains homozygous for the respective mutations in the Xirp2 gene.

Analysis of CRISPR/Cas9-generated Xirp2-null mice

To confirm that XIRP2 protein expression was abolished in the Xirp2 mutant mice, we performed immunocytochemistry experiments on cochlear and utricular whole mounts using two antibodies that recognized different epitopes in the short XIRP2 isoform. As demonstrated in Figure 9, XIRP2 protein immunoreactivity in the stereocilia was completely abolished in homozygous mutants. It is of particular interest that the immunoreactivity of the antibody recognizing an epitope on exon -6 , positioned upstream of the CRISPR/Cas9-mediated mutation, was abolished in the mutant mice, demonstrating that the truncated $\mathrm{N}$-terminal part of XIRP2, which would have resembled the protein product of the putative Gm1322 gene, was degraded. In the cochleae of mutant Xirp2 mice, residual immunoreactivity was seen in hair cell bodies with each antibody (Fig. 9B), which is likely to be caused by nonspecific antibody binding. All three mutant Xirp2 mouse lines derived from the CRISPR experiment lacked XIRP2 immunoreactivity in hair cell stereocilia. Finally, we performed Western blot analysis with whole utricle lysates from WT and Xirp2-null mice, detecting with the D-18 XIRP2 antibody. A band consistent with 

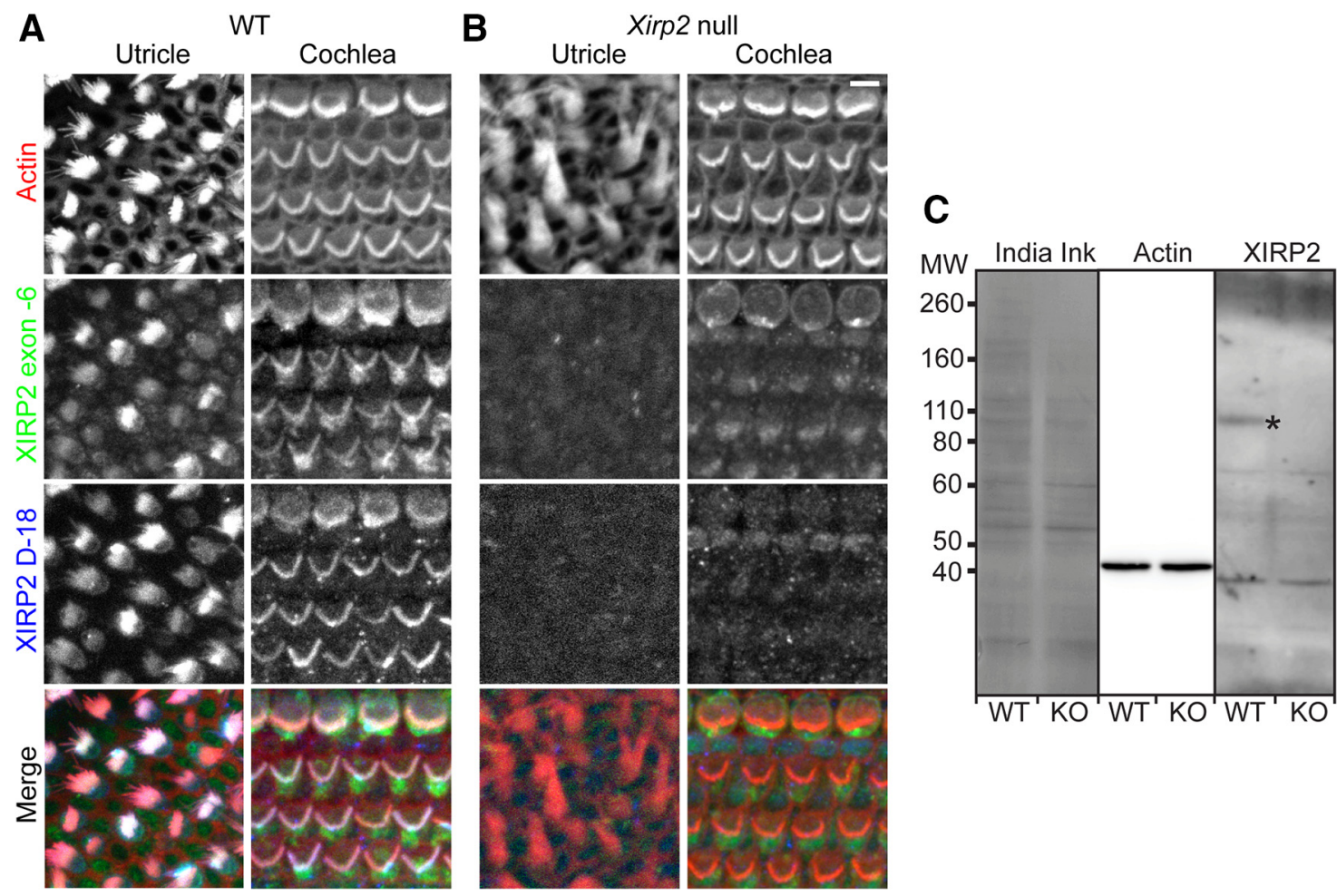

Figure 9. XIRP2 expression is abolished in hair cells of homozygous Xirp2 mutant mice. $\boldsymbol{A}, \boldsymbol{B}$, Immunocytochemistry for XIRP2 expression in WT $(\boldsymbol{A})$ and null $(\boldsymbol{B})$ mice in P4 cochlea and utricle explants. Experiments were performed with the D-18 antibody and with an antibody recognizing an epitope encoded by exon -6 , upstream of the site edited in the Xirp2 gene. XIRP2 immunoreactivity is detected with both antibodies in WT cochlear and vestibular hair bundles $(\boldsymbol{A})$. Immunoreactivity with both antibodies was abolished in hair bundles of Xirp2-null mice $(\boldsymbol{B})$. Remaining background staining was similar to that seen in WT tissue. Scale bar, $5 \mu \mathrm{m}$. C, Western blot analysis (using the D-18 antibody) of whole utricle lysates from WT and Xirp2-null mice, indicating loss of a band consistent with the size of short XIRP2 (asterisk) in the Xirp2-null lysate. The long XIRP2 isoform, also present in the whole utricle, is not detected, possibly due to insufficient expression levels. India Ink stain (total protein) and the $\beta$-actin-specific band indicate equal loading.

the expected mass of the short XIRP2 isoform $(\sim 105 \mathrm{kDa})$ was present in the WT, but absent in the Xirp2-null utricle lysate (Fig. 9C).

\section{Ultrastructural analysis of stereocilia of Xirp2-null mice}

We examined the morphology of the cochlea and utricle in Xirp2null mice using SEM. Although XIRP2 is expressed during embryonic development of the hair cell and continues to be expressed in mature hair cells, the gross morphology of the sensory epithelium was not affected in Xirp2-null mice, indicating that XIRP2 is not essential for hair cell development and hair bundle morphogenesis (Fig. 10 B,C). However, we found that outer hair cell stereocilia in the mid-basal turns of the cochlea of 12-d-old mutant mice displayed signs of degeneration, when compared with WT controls (Fig. 10D-H); this effect was greatest in the shortest row of stereocilia in the mid-basal to basal cochlear turns (Fig. 10G). In 8-week-old mice, in addition to the degeneration of the shortest stereocilia of outer hair cells, we detected occasional missing outer hair cell bundles in the midbasal turns of the cochlea (Fig. 10I).

\section{Xirp2-null mice develop high-frequency hearing loss}

Hearing in Xirp2-null, heterozygous, and WT control mice was tested using ABR measurements. When compared with WT and heterozygous controls, Xirp2-null mice older than 7-8 weeks displayed statistically significant elevated thresholds at $32 \mathrm{kHz}$ (Fig. $10 \mathrm{~K}$ ), while differences reached significance at $22.4 \mathrm{kHz}$ only in 9- to 10 -week-old mice (Fig. $10 \mathrm{~J} ; n=7$ for each genotype). Hearing loss did not extend to lower frequencies, however (data not shown). These data were consistent with the pattern of stereocilia degeneration. While we compared littermates in the ABR analy- sis, the CRISPR/Cas9-generated mice are on a mixed background (albino C57BL/6J and SJL). Because known modifier genes are present in the C57BL/6J strain (ahl; Johnson et al., 1997, 2006), some variability in hearing loss of all three genotypes could be due to additional mutant genes. To at least account for one of the strongest known modifiers, the $C d h 23^{\text {ahl }}$ variant (Noben-Trauth et al., 2003), we sequenced the Cdh23 locus and excluded any mice that were homozygous for the $C d h 23^{\text {ahl }}$ allele from the analysis. Because off-target mutations have been reported with CRISPR/Cas9 technology (Fu et al., 2013; Hsu et al., 2013), we sequenced 15 potential off-target sites, identified using an algorithm developed in the Zhang lab (CRISPR Design; Hsu et al., 2013), from each of our three founder mice; no mutations were found (see list of potential off-target sites in the Materials and Methods section). In conclusion, we have successfully used the novel CRISPR/Cas9 technology to generate mice with a deleterious mutation in the Xirp2 gene, and established the importance of the XIRP2 protein for long-term maintenance of highfrequency hearing.

\section{Discussion}

In this study, we investigated the expression, localization, and in vivo function of a novel hair cell protein called XIRP2. XIRP2 was previously reported to be specifically expressed in the striated muscle, where it is located at the Z-disk and the intercalated disk (Huang et al., 2006; Q. Wang et al., 2010, 2012). Here we directly implicate XIRP2 in hearing function. XIRP2 is expressed in the developing and mature hair cell, spatially restricted to the stereocilium, cuticular plate, and circumferential actin belt region of the hair cell. A combination of peptide mass spectrometry, RNA 

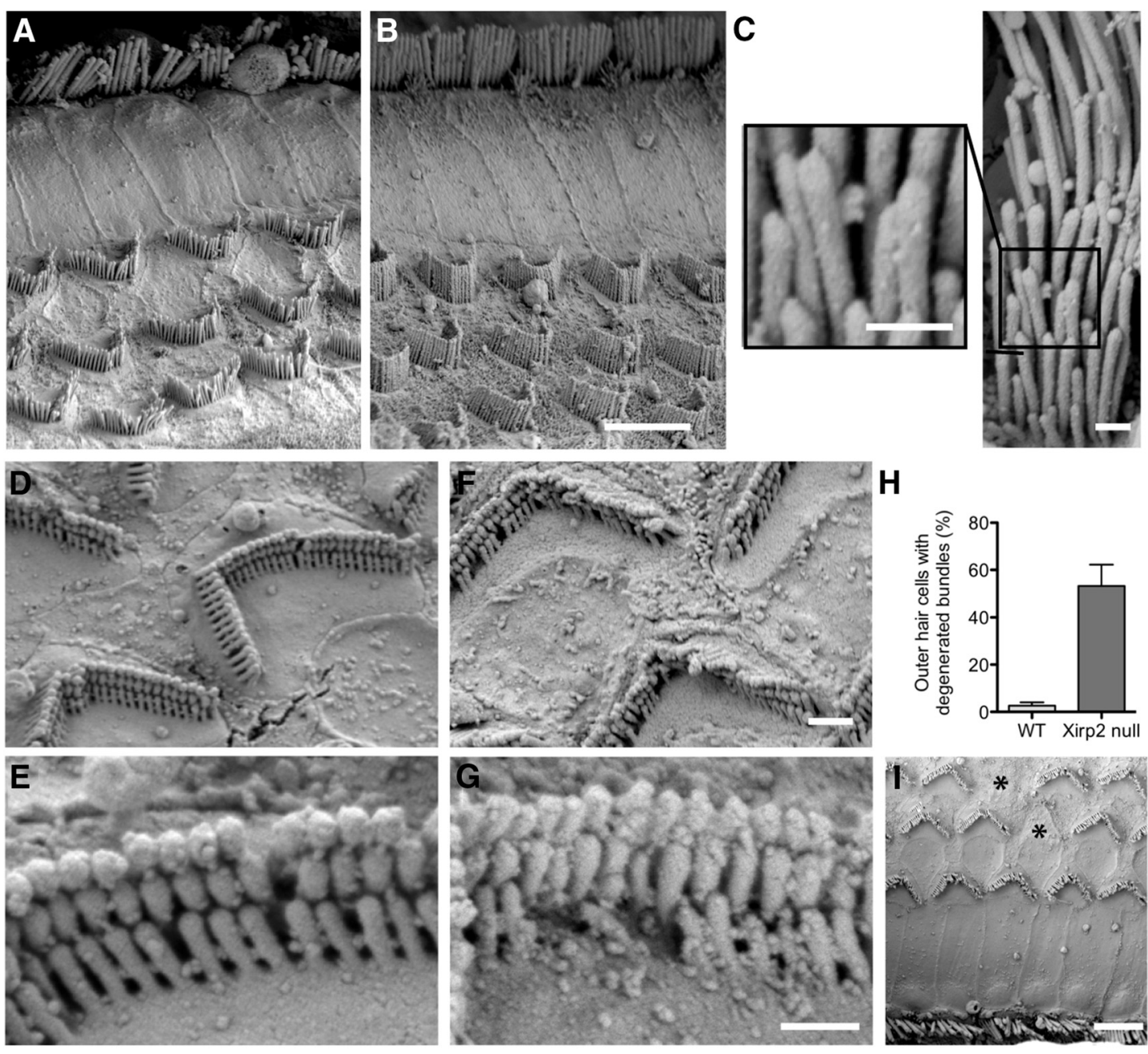

$\square$ 5-6 wks

$\square$ 7-8 wks

$\mathbf{J}$ $22.4 \mathrm{kHz}$

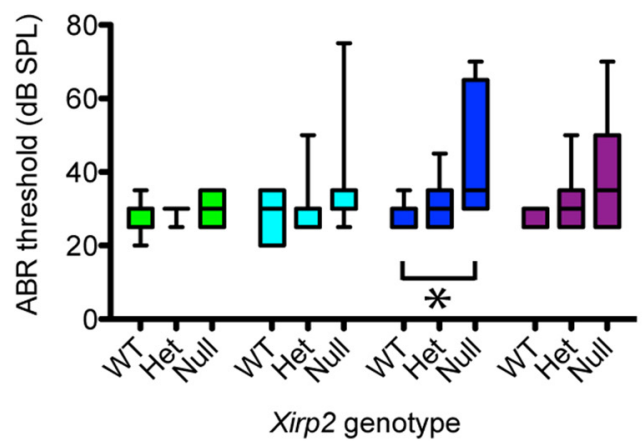

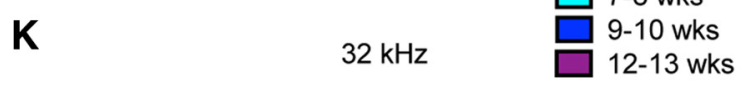

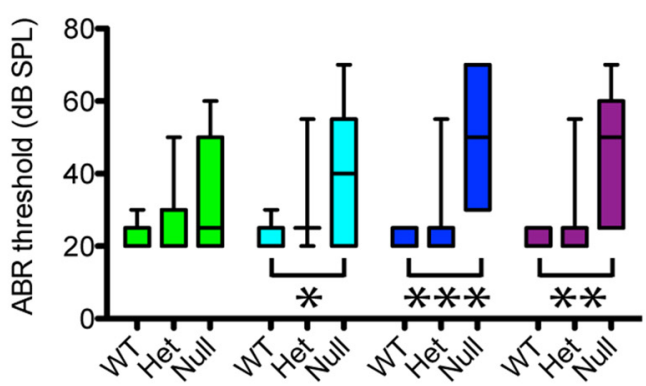

Xirp2 genotype

Figure 10. Xirp2-null mice display stereocilia degeneration and high-frequency hearing loss. $A, B, S E M$ micrographs of the mid-apical turn in WT $(\boldsymbol{A})$ and Xirp2-null mutant mice ( $\boldsymbol{B})$, showing that overall cochlear morphology is not affected in mutantmice. Scale bar, $5 \mu \mathrm{m}$. C, Hair bundles of Xirp2-null utricle haircells appear normal; tenting at stereocilia tips suggests that tip links were present. Scale bars: $0.5 \mu \mathrm{m}$. $D, E$, Mid-basal cochlear turn of WT mice show three distinct rows of outer hair cell (OHC) stereocilia. $F, G, 0 H C$ stereocilia from homozygous Xirp2-null mice display degeneration, especially in the row of shortest stereocilia. Scale bar, $\boldsymbol{F}, 1 \mu \mathrm{m} ; \boldsymbol{G}, 0.5 \mu \mathrm{m}$. $\boldsymbol{H}$, Quantification of stereocilia degeneration. A hair cell with at least two misformed/shortened stereocilia was scored as degenerated. ${ }^{* * *} p$ value $<0.0001$ in an unpaired $t$ test. $I$, Xirp2-null mice also showed signs of sporadic $0 H C$ Chair bundle loss in the mid-basal turn of the cochlea (asterisks). Scale bar, $5 \mu \mathrm{m}$. $J, K$, Auditory brainstem response analysis of homozygous Xirp2-null mice revealed a significant threshold shift at $9-10$ weeks of age at $22.4 \mathrm{kHz}(\boldsymbol{\eta})$, and $7-8$ weeks of age (and later) at $32 \mathrm{kHz}(\boldsymbol{K})$, when compared with WT and heterozygous (Het) control animals (null mice: $n=7$, Het mice: $n=7$, WT mice: $n=7$; only male mice were used). ${ }^{* * *} p$ value $<0.001$, ${ }^{* *} p$ value $<0.01$, and ${ }^{*} p$ value $<0.05$ in an unpaired $t$ test.

transcript analysis, and isoform-specific immunolocalization demonstrated that the hair cell expresses at least two distinct isoforms: The cuticular plate and pericuticular necklace region host a long XIRP2 isoform that closely resembles that described in myocytes (Huang et al., 2006; Q. Wang et al., 2012). The hair bundle, however, uses a variant that lacks the characteristic Xinrepeat domain, which mediates the binding to all published interactors of XIRP2, including actin, $\alpha$-actinin, nebulin/nebulette, $\beta$-catenin, and p120-catenin (Pacholsky et al., 2004; Cherepanova et al., 2006; Choi et al., 2007; Grosskurth et al., 2008; 
Eulitz et al., 2013; Q. Wang et al., 2014). The large difference between the splice forms suggests that each fulfills a distinct function. In the pericuticular necklace region, based on colocalization with $\alpha$-actinin and NMII, the long XIRP2 isoform appears to be associated with adherens junctions. Notably, the cellular sites occupied by the long XIRP2 splice form-the Z-disk and intercalated disk in cardiomyocytes, and the adherens junction at the hair cell/supporting cell junction-are "mechanical hotspots," exposed to lifelong mechanical strain, caused by myogenic contractions in the heart and sound-induced vibrations of the basilar membrane, respectively. XIRP2 may contribute to the mechanical resilience or maintenance of these structures, possibly involving the numerous Xin repeats.

What then is the role of the short XIRP2 splice form in the stereocilia? Its preferential localization to the actin-membrane interface and its lack of actin-binding Xin repeats both argue against a role in F-actin cross-linking. One possibility is that XIRP2 is an actin-to-membrane connector, decorating the periphery of the actin core to prevent spontaneous depolymerization and branching. Such a function would be reminiscent of the function of LIMA1 (EPLIN), a paralog of short XIRP2, which binds to F-actin and prevents its depolymerization (Maul et al., 2003; Chervin-Pétinot et al., 2012). XIRP2 might also act as a mechanical connector for the actin cytoskeleton to the membrane; XIRP2 would carry out this function in parallel with the ezrin/radixin/moesin proteins, which already occupy that functional niche in stereocilia (Kitajiri et al., 2004; Pataky et al., 2004; Shin et al., 2007; Niggli and Rossy, 2008; Salles et al., 2014).

When expressed in the HEK293 or CL4 cells, the short XIRP2 isoform, despite the lack of the Xin-repeat domain reported to be important for actin and $\alpha$-actinin binding, continues to colocalize with F-actin-rich structures. Future studies will address whether XIRP2 binds directly to F-actin and will identify functional domains in addition to the LIM domain. Interestingly, heterologously expressed short XIRP2 does not localize to the distal parts of the filopodia in HEK293 cells, and in CL4 cells, XIRP2 is restricted to the rootlet portion of the microvilli. However, when GFP-tagged XIRP2 is introduced into hair cells using a gene gun, it is effectively targeted throughout the stereocilia. We thus conclude that the localization of the short XIRP2 isoform to the stereocilia is facilitated by steric or biochemical factors that are not present in CL4 microvilli but are present in hair cell stereocilia.

An interesting question is how the two isoforms are differentially targeted to their respective sites in the hair cell. The long XIRP2 isoform, which is known to cross-link F-actin into a loose, gel-like organization (Pacholsky et al., 2004), might be sterically hindered from entering the paracrystalline structure of the parallel actin bundles in the stereocilium. In addition, the long XIRP2 isoform might be specifically retained at the adherens junction and cuticular plate by bimodal binding, through its Xinrepeat domains, to F-actin, NMII, or $\alpha$-actinin, which are known components of the cuticular plate and the adherens junction at the hair cell junction, but excluded from the stereocilia. Interestingly, XIRP2-immunoreactive foci at the apical junction localize closer to NMII than $\alpha$-actinin (Fig. 5B). It was recently reported that the apical junction in the cochlear epithelium is organized in a fashion similar to muscle sarcomeres, in that NMII, constituting the hair cell's equivalent of the M-line, alternates with actin and $\alpha$-actinin, which are localized at the hair cell's equivalent of the Z-disk (Ebrahim et al., 2013). We propose that the C terminus of the long XIRP2 binds to $\alpha$-actinin embedded in the Z-disk, with the Xin repeats coextending with F-actin; in contrast, the $\mathrm{N}$ terminus, recognized by the D-18 antibody, may be positioned closer to the M-line, which explains the D-18 colocalization with NMII (rather than $\alpha$-actinin) in triple-labeling experiments. Such a model is reminiscent of the role of nebulin, which is believed to act as a regulator of thin filament length and Z-disk structure (Labeit et al., 2011). A concerted role of XIRP2 and nebulin is supported by the fact that these two proteins interact with each other (Eulitz et al., 2013), and contain repeat domains (Xin repeats in XIRP2 and nebulin-like repeats in nebulin) that bind F-actin in a similar manner (Cherepanova et al., 2006).

To elucidate the role of XIRP2 in hearing function in vivo, we used CRISPR/Cas9 technology to create a functional Xirp2-null mutant mouse line. The introduction of the CRISPR/Cas technology has dramatically accelerated the generation of genetically modified mice. Because off-target effects are regarded as the most serious concern when using the CRISPR/Cas9 technology (Fu et al., 2013; Hsu et al., 2013), we have addressed this issue using several strategies. First, when designing the targets, we adhered to a set of rules established by the Zhang lab that minimize off-target editing (Hsu et al., 2013). Second, we genotyped 15 potential off-target sites, but did not find any off-target mutations; even had we identified any, undesired off-target mutations could have been bred out in most cases.

Our Xirp2 mutant mice exhibited a moderate hearing loss at high frequencies. The mild phenotype of the Xirp2 deletion was somewhat surprising considering its distinct localization and relative abundance in the hair bundle. However, previous studies have shown that actin-associated proteins fulfill redundant functions in the stereocilium: a hypomorphic mutation in the gene for the actin cross-linker FSCN2 causes only mild defects (Shin et al., 2010), and the complete deletion of the gene for PLS1, the most abundant actin cross-linker in the mouse stereocilium, causes only a moderate form of hearing loss in mice (Taylor et al., 2015). Proteins involved in cross-linking and maintaining F-actin may be so crucial to stereocilia function that their respective functions are secured by redundancy.

In addition to hair bundle degeneration, loss of XIRP2 function at the cellular junctions could contribute to the progressive high-frequency hearing loss, possibly by compromising the epithelial barrier. Future studies, perhaps using mice with splice form-specific mutations in the Xirp2 gene, will be required to tease apart such possibilities.

Due to nonspecific reactivity of the XIRP2 antibodies used in this study, it is difficult to prove that our Xirp2 mutant mouse model entirely lacks XIRP2 protein expression. While isoforms unaffected by the mutation might conceivably still be expressed in mutant hair cells, this is unlikely. First, the introduced mutation is downstream of the start sites of all known database entries of Xirp 2 transcripts, thus is expected to cause premature termination of all isoforms. XIRP2 immunoreactivity in the hair bundle was abolished in mutant mice, and no additional immunoreactivity was detected in the mutant tissue in Western blot and immunocytochemistry analysis. We therefore conclude that in the Xirp2 mutant mice generated in this study, the hair bundle lacks XIRP2 entirely, and it is likely that no XIRP2 splice variant is expressed elsewhere. Interestingly, our Xirp2-null mice are healthy and do not show any additional pathological signs, such as the growth retardation and early postnatal death observed in a different Xirp2 KO mouse (Q. Wang et al., 2010). While differences in strain background may account for this discrepancy, our mice are nevertheless useful in determining how XIRP2 maintains stereocilia integrity.

Two human deafness loci, DFNB27 and DFNA16, map to the XIRP2 gene locus. Regardless of whether future studies identify 
mutations in XIRP2 as causative for these deafness forms, study of XIRP2 function in hair cells should uncover mechanisms by which subtle defects caused by genetic and environmental factors can compromise the structural integrity of hair cell structures over time, which is significant for understanding the mechanistic basis of age and noise-induced hearing loss in humans.

\section{References}

Barrangou R, Fremaux C, Deveau H, Richards M, Boyaval P, Moineau S, Romero DA, Horvath P (2007) CRISPR provides acquired resistance against viruses in prokaryotes. Science 315:1709-1712. CrossRef Medline

Brouns SJ, Jore MM, Lundgren M, Westra ER, Slijkhuis RJ, Snijders AP, Dickman MJ, Makarova KS, Koonin EV, van der Oost J (2008) Small CRISPR RNAs guide antiviral defense in prokaryotes. Science 321:960964. CrossRef Medline

Bullen A, Taylor RR, Kachar B, Moores C, Fleck RA, Forge A (2014) Inner ear tissue preservation by rapid freezing: improving fixation by highpressure freezing and hybrid methods. Hear Res 315:49-60. CrossRef Medline

Cherepanova O, Orlova A, Galkin VE, van der Ven PF, Fürst DO, Jin JP, Egelman EH (2006) Xin-repeats and nebulin-like repeats bind to F-actin in a similar manner. J Mol Biol 356:714-723. CrossRef Medline

Chervin-Pétinot A, Courçon M, Almagro S, Nicolas A, Grichine A, Grunwald D, Prandini MH, Huber P, Gulino-Debrac D (2012) Epithelial protein lost in neoplasm (EPLIN) interacts with $\alpha$-catenin and actin filaments in endothelial cells and stabilizes vascular capillary network in vitro. J Biol Chem 287:7556-7572. CrossRef Medline

Choi S, Gustafson-Wagner EA, Wang Q, Harlan SM, Sinn HW, Lin JL, Lin JJ (2007) The intercalated disk protein, mXinalpha, is capable of interacting with beta-catenin and bundling actin filaments. J Biol Chem 282: 36024-36036. CrossRef Medline

Cong L, Ran FA, Cox D, Lin S, Barretto R, Habib N, Hsu PD, Wu X, Jiang W, Marraffini LA, Zhang F (2013) Multiplex genome engineering using CRISPR/Cas systems. Science 339:819-823. CrossRef Medline

Cox J, Mann M (2008) MaxQuant enables high peptide identification rates, individualized p.p.b.-range mass accuracies and proteome-wide protein quantification. Nat Biotechnol 26:1367-1372. CrossRef Medline

Davies S, Forge A (1987) Preparation of the mammalian organ of Corti for scanning electron microscopy. J Microsc 147:89-101. CrossRef Medline

Dror AA, Avraham KB (2009) Hearing loss: mechanisms revealed by genetics and cell biology. Annu Rev Genet 43:411-437. CrossRef Medline

Dumont RA, Lins U, Filoteo AG, Penniston JT, Kachar B, Gillespie PG (2001) Plasma membrane Ca2+-ATPase isoform 2a is the PMCA of hair bundles. J Neurosci 21:5066-5078. Medline

Ebrahim S, Fujita T, Millis BA, Kozin E, Ma X, Kawamoto S, Baird MA, Davidson M, Yonemura S, Hisa Y, Conti MA, Adelstein RS, Sakaguchi H, Kachar B (2013) NMII forms a contractile transcellular sarcomeric network to regulate apical cell junctions and tissue geometry. Curr Biol 23: 731-736. CrossRef Medline

Eulitz S, Sauer F, Pelissier MC, Boisguerin P, Molt S, Schuld J, Orfanos Z, Kley RA, Volkmer R, Wilmanns M, Kirfel G, van der Ven PF, Fürst DO (2013) Identification of Xin-repeat proteins as novel ligands of the $\mathrm{SH} 3$ domains of nebulin and nebulette and analysis of their interaction during myofibril formation and remodeling. Mol Biol Cell 24:3215-3226. CrossRef Medline

Friedman TB, Griffith AJ (2003) Human nonsyndromic sensorineural deafness. Annu Rev Genomics Hum Genet 4:341-402. CrossRef Medline

Fu Y, Foden JA, Khayter C, Maeder ML, Reyon D, Joung JK, Sander JD (2013) High-frequency off-target mutagenesis induced by CRISPR-Cas nucleases in human cells. Nat Biotechnol 31:822-826. CrossRef Medline

Fukushima K, Kasai N, Ueki Y, Nishizaki K, Sugata K, Hirakawa S, Masuda A, Gunduz M, Ninomiya Y, Masuda Y, Sato M, McGuirt WT, Coucke P, Van Camp G, Smith RJ (1999) A gene for fluctuating, progressive autosomal dominant nonsyndromic hearing loss, DFNA16, maps to chromosome 2q23-24.3. Am J Hum Genet 65:141-150. CrossRef Medline

Gillespie PG, Walker RG (2001) Molecular basis of mechanosensory transduction. Nature 413:194-202. CrossRef Medline

Grosskurth SE, Bhattacharya D, Wang Q, Lin JJ (2008) Emergence of Xin demarcates a key innovation in heart evolution. PLoS One 3:e2857. CrossRef Medline

Horvath P, Barrangou R (2010) CRISPR/Cas, the immune system of bacteria and archaea. Science 327:167-170. CrossRef Medline
Hsu PD, Scott DA, Weinstein JA, Ran FA, Konermann S, Agarwala V, Li Y, Fine EJ, Wu X, Shalem O, Cradick TJ, Marraffini LA, Bao G, Zhang F (2013) DNA targeting specificity of RNA-guided Cas9 nucleases. Nat Biotechnol 31:827-832. CrossRef Medline

Huang HT, Brand OM, Mathew M, Ignatiou C, Ewen EP, McCalmon SA, Naya FJ (2006) Myomaxin is a novel transcriptional target of MEF2A that encodes a Xin-related alpha-actinin-interacting protein. J Biol Chem 281:39370-39379. CrossRef Medline

Hudspeth AJ (1989) How the ear's works work. Nature 341:397-404. CrossRef Medline

Hwang WY, Fu Y, Reyon D, Maeder ML, Tsai SQ, Sander JD, Peterson RT, Yeh JR, Joung JK (2013) Efficient genome editing in zebrafish using a CRISPR-Cas system. Nat Biotechnol 31:227-229. CrossRef Medline

Jinek M, Chylinski K, Fonfara I, Hauer M, Doudna JA, Charpentier E (2012) A programmable dual-RNA-guided DNA endonuclease in adaptive bacterial immunity. Science 337:816-821. CrossRef Medline

Johnson KR, Erway LC, Cook SA, Willott JF, Zheng QY (1997) A major gene affecting age-related hearing loss in C57BL/6J mice. Hear Res 114:83-92. CrossRef Medline

Johnson KR, Zheng QY, Noben-Trauth K (2006) Strain background effects and genetic modifiers of hearing in mice. Brain Res 1091:79-88. CrossRef Medline

Kitajiri S, Fukumoto K, Hata M, Sasaki H, Katsuno T, Nakagawa T, Ito J, Tsukita S, Tsukita S (2004) Radixin deficiency causes deafness associated with progressive degeneration of cochlear stereocilia. J Cell Biol 166: 559-570. CrossRef Medline

Labeit S, Ottenheijm CA, Granzier H (2011) Nebulin, a major player in muscle health and disease. FASEB J 25:822-829. CrossRef Medline

Mali P, Yang L, Esvelt KM, Aach J, Guell M, DiCarlo JE, Norville JE, Church GM (2013) RNA-guided human genome engineering via Cas9. Science 339:823-826. CrossRef Medline

Mathers C, Smith A, Concha M (2001) Global burden of hearing loss in the year 2000. Geneva, Switzerland: WHO

Maul RS, Song Y, Amann KJ, Gerbin SC, Pollard TD, Chang DD (2003) EPLIN regulates actin dynamics by cross-linking and stabilizing filaments. J Cell Biol 160:399-407. CrossRef Medline

Morton CC, Nance WE (2006) Newborn hearing screening-a silent revolution. N Engl J Med 354:2151-2164. CrossRef Medline

Niggli V, Rossy J (2008) Ezrin/radixin/moesin: versatile controllers of signaling molecules and of the cortical cytoskeleton. Int J Biochem Cell Biol 40:344-349. CrossRef Medline

Noben-Trauth K, Zheng QY, Johnson KR (2003) Association of cadherin 23 with polygenic inheritance and genetic modification of sensorineural hearing loss. Nat Genet 35:21-23. CrossRef Medline

Pacholsky D, Vakeel P, Himmel M, Löwe T, Stradal T, Rottner K, Fürst DO, van der Ven PF (2004) Xin repeats define a novel actin-binding motif. J Cell Sci 117:5257-5268. CrossRef Medline

Pataky F, Pironkova R, Hudspeth AJ (2004) Radixin is a constituent of stereocilia in hair cells. Proc Natl Acad Sci U S A 101:2601-2606. CrossRef Medline

Pulleyn LJ, Jackson AP, Roberts E, Carridice A, Muxworthy C, Houseman M, Al-Gazali LL, Lench NJ, Markham AF, Mueller RF (2000) A new locus for autosomal recessive non-syndromal sensorineural hearing impairment (DFNB27) on chromosome 2q23-q31. Eur J Hum Genet 8:991993. CrossRef Medline

Raviv D, Dror AA, Avraham KB (2010) Hearing loss: a common disorder caused by many rare alleles. Ann N Y Acad Sci 1214:168-179. CrossRef Medline

Rzadzinska A, Schneider M, Noben-Trauth K, Bartles JR, Kachar B (2005) Balanced levels of Espin are critical for stereociliary growth and length maintenance. Cell Motil Cytoskeleton 62:157-165. CrossRef Medline

Salles FT, Andrade LR, Tanda S, Grati M, Plona KL, Gagnon LH, Johnson KR, Kachar B, Berryman MA (2014) CLIC5 stabilizes membrane-actin filament linkages at the base of hair cell stereocilia in a molecular complex with radixin, taperin, and myosin VI. Cytoskeleton 71:61-78. CrossRef Medline

Sekerková G, Richter CP, Bartles JR (2011) Roles of the espin actinbundling proteins in the morphogenesis and stabilization of hair cell stereocilia revealed in $\mathrm{CBA} / \mathrm{CaJ}$ congenic jerker mice. PLoS Genet 7:e1002032. CrossRef Medline

Shearer AE, Smith RJ (2012) Genetics: advances in genetic testing for deafness. Curr Opin Pediatr 24:679-686. CrossRef Medline 
Shin JB, Streijger F, Beynon A, Peters T, Gadzala L, McMillen D, Bystrom C, Van der Zee CE, Wallimann T, Gillespie PG (2007) Hair bundles are specialized for ATP delivery via creatine kinase. Neuron 53:371-386. CrossRef Medline

Shin JB, Pagana J, Gillespie PG (2009) Twist-off purification of hair bundles. In: Auditory and vestibular research: methods and protocols (Sokolowski B, ed), pp 241-255. Totowa, NJ: Humana.

Shin JB, Longo-Guess CM, Gagnon LH, Saylor KW, Dumont RA, Spinelli KJ, Pagana JM, Wilmarth PA, David LL, Gillespie PG, Johnson KR (2010) The $\mathrm{R} 109 \mathrm{H}$ variant of fascin-2, a developmentally regulated actin crosslinker in hair-cell stereocilia, underlies early-onset hearing loss of DBA/2J mice. J Neurosci 30:9683-9694. CrossRef Medline

Shin JB, Krey JF, Hassan A, Metlagel Z, Tauscher AN, Pagana JM, Sherman NE, Jeffery ED, Spinelli KJ, Zhao H, Wilmarth PA, Choi D, David LL, Auer M, Barr-Gillespie PG (2013) Molecular architecture of the chick vestibular hair bundle. Nat Neurosci 16:365-374. CrossRef Medline

Steel KP, Kros CJ (2001) A genetic approach to understanding auditory function. Nat Genet 27:143-149. CrossRef Medline

Taylor R, Bullen A, Johnson SL, Grimm-Günter EM, Rivero F, Marcotti W, Forge A, Daudet N (2015) Absence of plastin 1 causes abnormal maintenance of hair cell stereocilia and a moderate form of hearing loss in mice. Hum Mol Genet 24:37-49. CrossRef Medline

Terns MP, Terns RM (2011) CRISPR-based adaptive immune systems. Curr Opin Microbiol 14:321-327. CrossRef Medline
Van Camp G, Willems PJ, Smith RJ (1997) Nonsyndromic hearing impairment: unparalleled heterogeneity. Am J Hum Genet 60:758-764. Medline

Wang H, Yang H, Shivalila CS, Dawlaty MM, Cheng AW, Zhang F, Jaenisch R (2013) One-step generation of mice carrying mutations in multiple genes by CRISPR/Cas-mediated genome engineering. Cell 153:910-918. CrossRef Medline

Wang Q, Lin JL, Reinking BE, Feng HZ, Chan FC, Lin CI, Jin JP, GustafsonWagner EA, Scholz TD, Yang B, Lin JJ (2010) Essential roles of an intercalated disc protein, mXinbeta, in postnatal heart growth and survival. Circ Res 106:1468-1478. CrossRef Medline

Wang Q, Lin JL, Wu KH, Wang DZ, Reiter RS, Sinn HW, Lin CI, Lin CJ (2012) Xin proteins and intercalated disc maturation, signaling and diseases. Front Biosci 17:2566-2593. CrossRef Medline

Wang Q, Lin JL, Chan SY, Lin JJ (2013) The Xin repeat-containing protein, $\mathrm{mXin} \beta$, initiates the maturation of the intercalated discs during postnatal heart development. Dev Biol 374:264-280. CrossRef Medline

Wang Q, Lin JL, Erives AJ, Lin CI, Lin JJ (2014) New insights into the roles of Xin repeat-containing proteins in cardiac development, function, and disease. Int Rev Cell Mol Biol 310:89-128. CrossRef Medline

Zheng L, Zheng J, Whitlon DS, García-Añoveros J, Bartles JR (2010) Targeting of the hair cell proteins cadherin 23 , harmonin, myosin XVa, espin, and prestin in an epithelial cell model. J Neurosci 30:7187-7201. CrossRef Medline 